\title{
PRICING RISK TRANSFER TRANSACTIONS ${ }^{1}$
}

\author{
BY \\ MORTON N. LANE \\ Lane Financial LLC, Kenilworth, USA
}

\section{INTRODUCTION}

Should the pricing of reinsurance catastrophes be related to the price of the default risk embedded in corporate bonds?

If not, why not?

A risk is a risk is a risk, in whatever market it appears. Shouldn't the riskprices in these different markets be comparable? More basically perhaps, how should reinsurance prices and bond prices be set? How does the market currently set them? These questions are central to the inquiry contained in this paper.

Avoiding unnecessary suspense, our answers are: Yes, cat prices should be related to credit prices because both risks contain a characteristic trade-off between the frequency of and severity of adverse events. We leave the question of how prices should be set to others and focus on the empirical question of how they have been set by the markets. In the process, we develop a fairly robust pricing mechanism and explore its potential uses in many different contexts.

The 1999 Insurance-Linked Securities (ILS) market (a.k.a., Cat Bond market) provides the empirical springboard to the discussion. The ILS market is only 4 years old. As such, it represents a new and unique intersection of reinsurance and financial markets. It provides a wonderful laboratory for exploring risk-pricing.

The ILS market, still in its experimental phase, appears to require more generous (cheap) pricing of insurance risk than does the bond market of default risk. So much so that academics have begun to weigh in on the question of why ${ }^{2}$. Previously, insurance pricing discussions had been confined to practicing insurance professionals, particularly actuaries ${ }^{3}$. For finance professionals, insurance pricing, much less reinsurance pricing, seldom made the index of their financial texts - though even that is beginning to change.

1 This paper was presented on June 22, 2000, as a keynote speech at the AFIR 2000 Colloquium in Tromsø, Norway.

2 See Bantwal \& Kunteuther (1) and Froot \& Posner (6).

${ }^{3}$ See Kreps (8) (9) and Mango (15).

ASTIN BULLETIN, Vol. 30, No. 2, 2000, pp. 259-293 


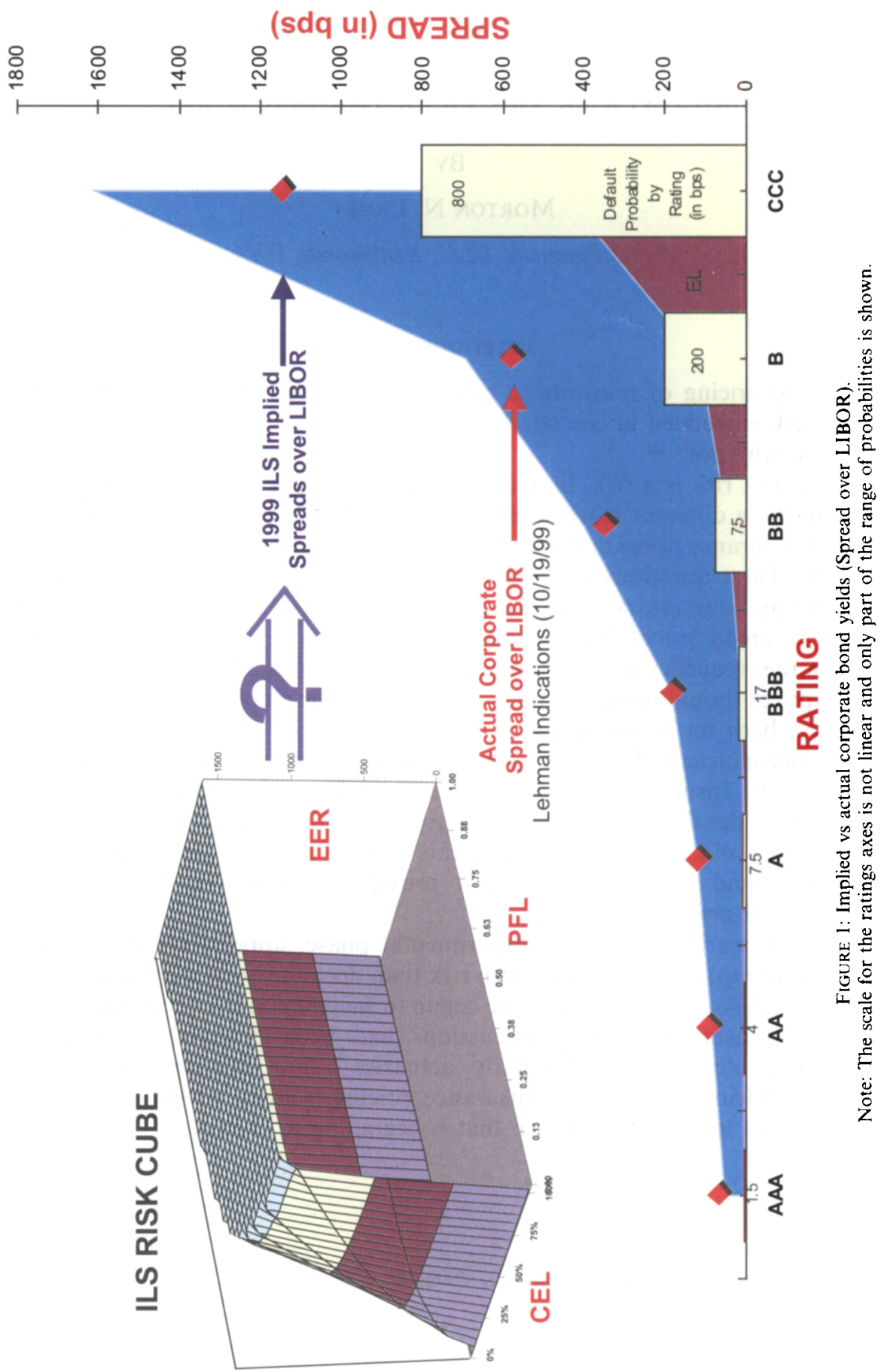


Perhaps academic reticence occurred because prior to the advent of cat bonds, reinsurance markets were opaque. Reinsurance prices were unavailable to the investing community. With insurance securitization, however, the pricing of embedded insurance risks is exposed to, and must be made appetizing for, investors. Prices ought to converge towards other alternative fixed income assets. At the very least, risk-pricing of insurance can now be compared with other investor alternatives. And yet, insurance is different.

\section{Insurance is Different?}

Any appraisal of the risks contained in insurance or reinsurance covers must take into account the fact that the statistical distribution of profit and loss outcomes may be severely skewed. Conventional risk measurement (i.e., the standard deviation) deals with random outcomes that are symmetric in nature. Price volatility is usually viewed as symmetric. Event or outcome risk (a characteristic of insurance) is not. How is the asymmetry to be captured? What are the components of event-risk and how do they factor into price? Indeed, how should "price" be articulated?

There is general agreement that the "price" of an insurance-linked security is the spread over and above (a) the risk-free rate and (b) the loss expected from the insurance. There is also general agreement that this "excess spread" is a function of, and reward for, the risk assumed. But how is that excess spread calculated and evaluated?

The most conventional - and respectable - risk measure is the standard deviation of outcomes. It is analytically convenient for portfolio as well as individual investment evaluation. And yet, its original promoter, Harry Markovitz, preferred the semi-variance to capture asymmetries. Its popularizer William Sharpe has largely confined its application to price-risk, which may be largely viewed as symmetrical in behavior.

In a pioneering work for actuarial literature, Rodney Kreps (Kreps (8) and (9)) tried to relate reinsurance pricing to capital markets. (This was largely before the ILS market existed.) His rationale was that the deployment of riskcapital in underwriting should be related to the deployment of risk-capital in investments. Indeed, it should. The ILS market gives us the first opportunity to see whether it actually does.

Kreps' analysis led (in general terms) to the conclusion that the "excess spread" should be a fraction of the standard deviation of the outcomes of the cover being reviewed. Furthermore, for a wide range of parameter choices, that fraction would likely be in the order of $20 \%$ to $40 \%$ of the standard deviation. This is the equivalent of saying that cat bonds should have Sharpe Ratios ${ }^{1}$ around 0.3 . But, in a remarkable example of the "dog that didn't bark" theory,

1 Care must be taken in defining the exact interpretation of the Sharpe Ratio that particular analysts use. Here it is the ratio of excess spread to standard deviation arising from credit events. It does not include returns on volatility from interest rate risk. 
no single private placement memorandum (PPM) of a 1999 ILS transaction provided standard deviation as a risk measure for investor consideration. All PPMs offered frequency risk and expected loss as risk measures for investors.

\section{Antecedents}

The antecedents of this paper explored the use of standard deviation in the context of the first ILS in 1996 ("A Year of Structuring Furiously").

As more securitizations emerged, it became clear that standard deviation was not entirely adequate for the insurance task. Our 1997 annual review paper ("Price, Risk, and Ratings for Insurance-Linked Notes") began to explore the use of Conditional Expected Loss (CEL) as a better measure for asymmetric insurance risk embedded in insurance-linked notes. Appealing as it was, it was not robust enough. This led to the joint consideration of two risk measures - the CEL and the probability of first dollar loss (PFL) in our 1998 paper, "Risk Cubes". (In retrospect, our 1997 enthusiasm for the CEL may have arisen because so many of that year's deals were pitched at the same PFL level.) This year's review of the 1999 securitizations continues the two-way (CEL and PFL) risk analysis addressed in 1998.

\section{Empirical Approach}

The conditional expected loss (CEL) is known more familiarly as severity of loss. The probability of first dollar loss (PFL) is referred to as frequency of loss. The influence of frequency and severity on risk assessments is not a new idea. Indeed, it is very old. What is fresh, however, is the use of transacted market prices as a mechanism for empirically measuring how the market makes a tradeoff between these two components of risk. A "revealed risk-preference" function is derived.

This risk preference function will be familiar to economists. It is similar to the Cobb-Douglas Production function. This workhorse of economics illustrated to generations of students how a trade-off is made between capital and labor to optimize production. Here a trade-off is made between frequency and severity to best explain preferred risk return positions (i.e., transacted prices).

What adds wind to our analytical sail is that the empirical insights derived from the ILS market may be useful in other apparently unrelated fixed income markets. Default risk (a.k.a., credit risk) is asymmetric whether it emanates from simple corporate bonds, CBOs or leveraged loans.

Here is the pricing that should bear some relation to the ILS market.

In a "David tells Goliath what to do" exercise, this paper presents a revealed risk preference that emanates from the 1999 ILS pricing and tries to predict bond prices. The results are tantalizing. Although not entirely scientific, the results certainly motivate further research. The bond market is, of course, a bigger and more volatile market than the ILS market. Revealed risk preferences from bonds should dictate ILS prices not the other way around. 
That is the prospect that is held out by our approach - that empirical studies of both markets may lead to revealing a "universal risk-pricing grid".

\section{Outline}

These ideas are presented in three parts. The first reviews the ILS securities issued in 1999. (Note that Lane \& Beckwith (10) put the securities in the context of current trends.) Readers more interested in the concepts may conveniently skip to the next section. Part Two fits a risk preference function to the 1999 data. It also develops some of the uses to which such a fit might be put. Finally, in Part Three the implications of the risk preference approach is explored in the framework of corporate bonds. We conclude with some opinions about the way the rating agencies can use this approach to improve their rating categories of insurance-linked (and perhaps other) securities.

Some caveats are in order. First, the risks described herein may be considered to be non-hedgeable, or more precisely, locally non-hedgeable because they are event-driven. They are not, therefore, susceptible to well-known options pricing models (e.g., Black Scholes, et al.). Neither is there an attempt to establish equilibrium pricing or portfolio effects - all of which we consider to be important - but beyond our present scope. The attempt is simply to suggest a form of, and a mechanism for, measuring the market's utility function for risk. In any such exercise, it is relative pricing that is examined. Absolute risk-return trade-offs are for other parts of the market to decide upon.

\section{PART I: REVIEWING THE INSURANCE SECURITIZATIONS OF 1999}

The (re)insurance securitizations of 1999 are listed in Table 1. Approximately $\$ 2.0$ billion of insurance risk was transferred to the capital markets in approximately a dozen transactions. The word "approximately" is used to signal the fact that full details may not be available about known deals, and not all deals may be known. (After all, the market is a private placement market.)

Table 1 details for each transaction (and any tranches), the Special Purpose Reinsurer (the name by which the deals are often known), the ceding company, lead underwriters, amount, ratings given, date of issue and maturity, together with various financial statistics. Certain of the financial statistics have been obtained directly from the PPM. Two statistics, "Expected Excess Return" (EER) and "Conditional Expected Loss" (CEL) are derived numbers.

In certain transactions, the term to maturity is different from the term for which the investor is on (insurance) risk. This was true of the Kelvin transaction. The senior Kelvin tranche could not go on risk until the second year of the threeyear term to maturity. The noteholder was receiving coupons for all three years. In order to compare and contrast reinsurance-equivalent prices, Table 1 adjusts prices to reflect equivalent annual risk periods.

Another adjustment involved the conversion of LIBOR - by definition, based on 360-days accounting - to an actual 365-day count. This affected nearly all of the deals. The LIBOR component was also extracted from fixed coupon 


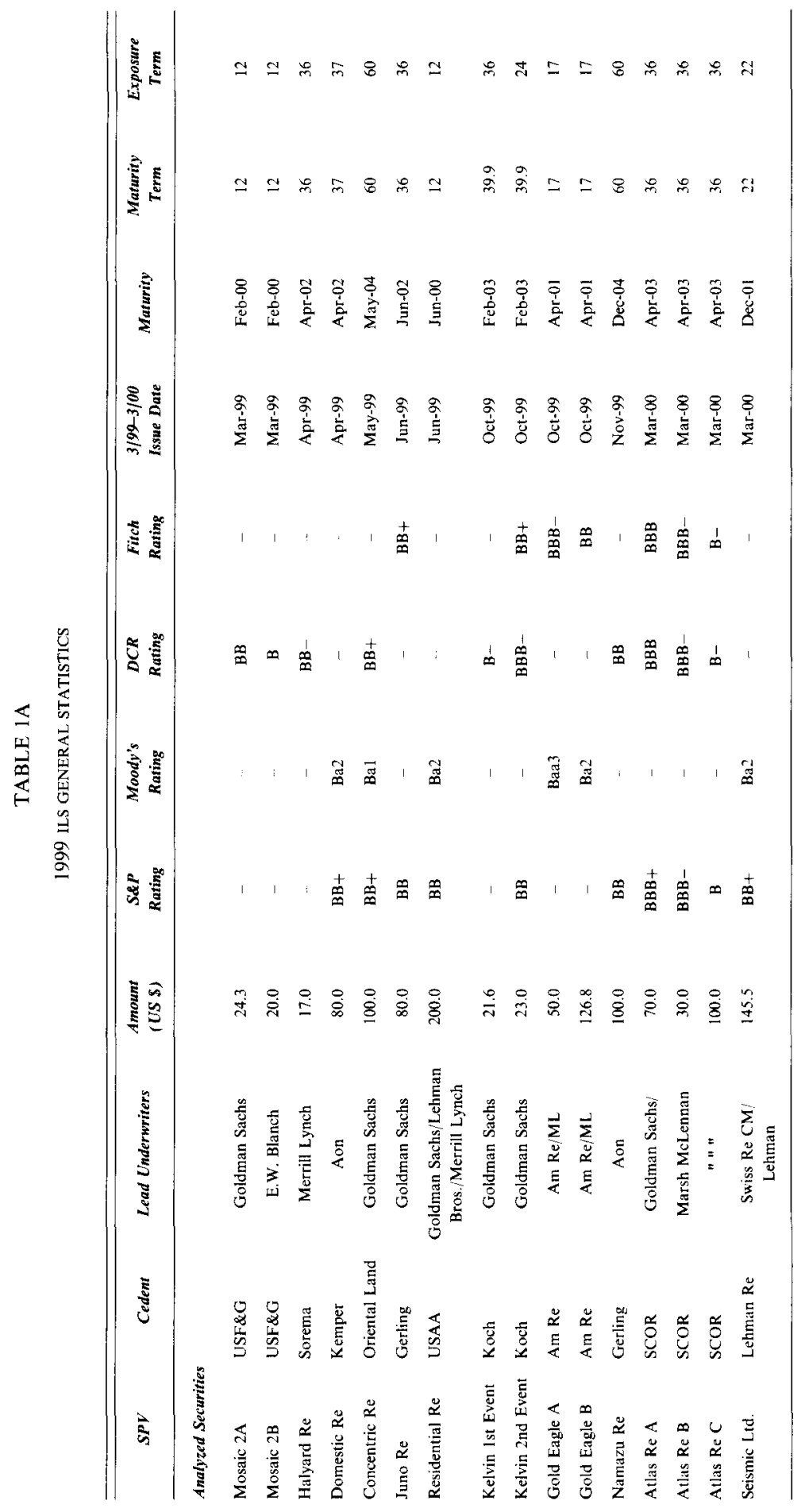


PRICING RISK TRANSFER TRANSACTIONS

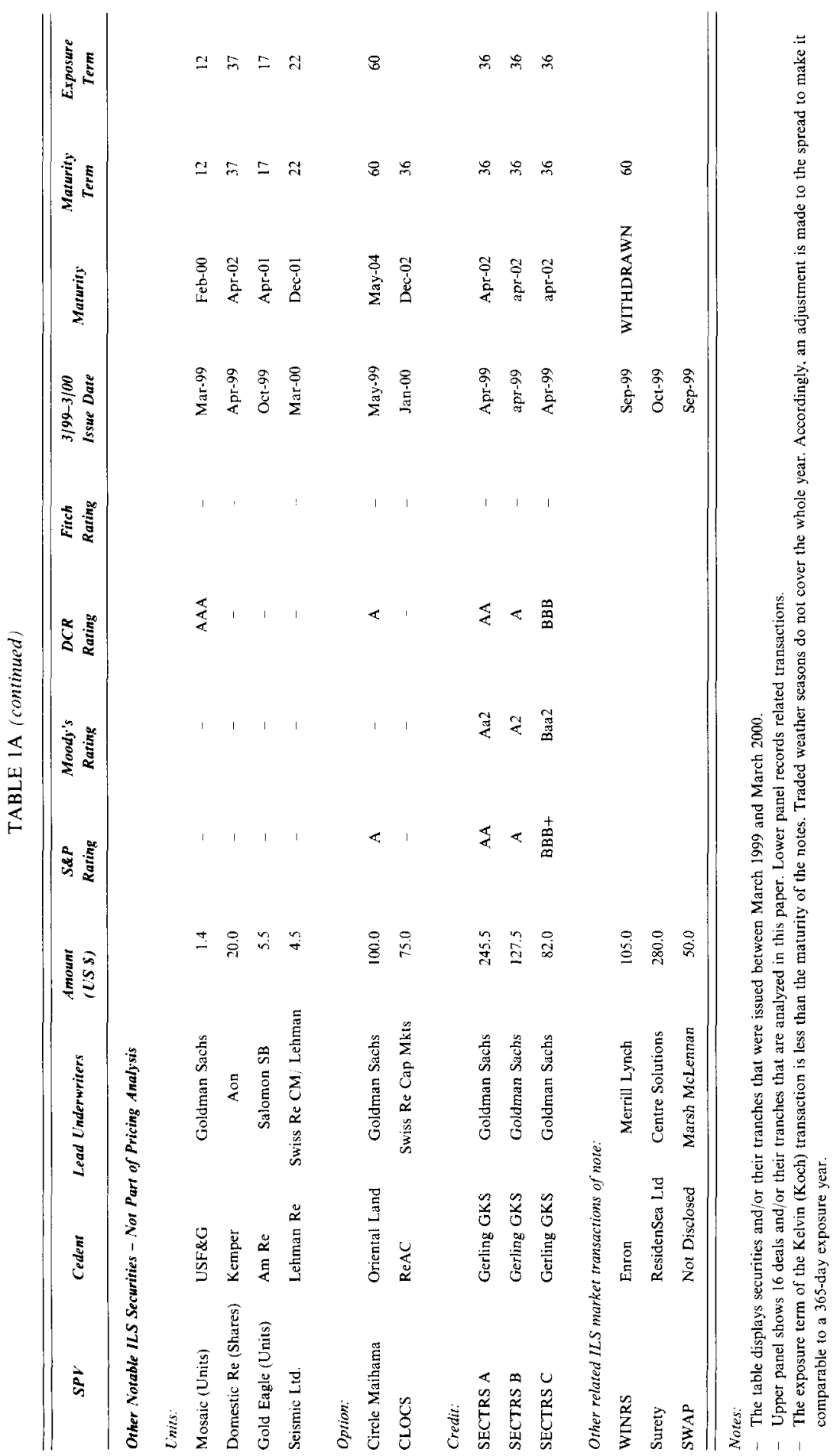




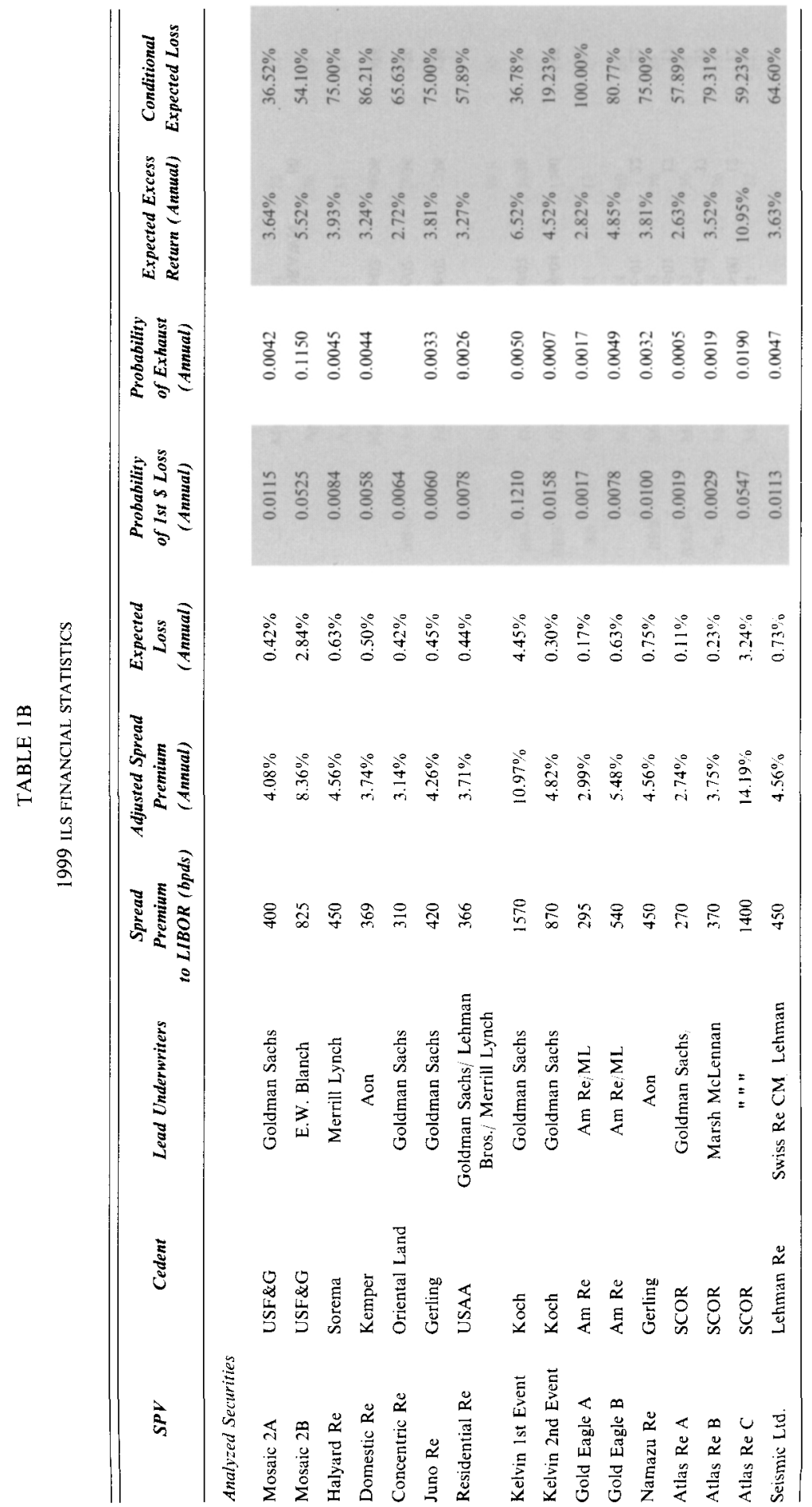


PRICING RISK TRANSFER TRANSACTIONS

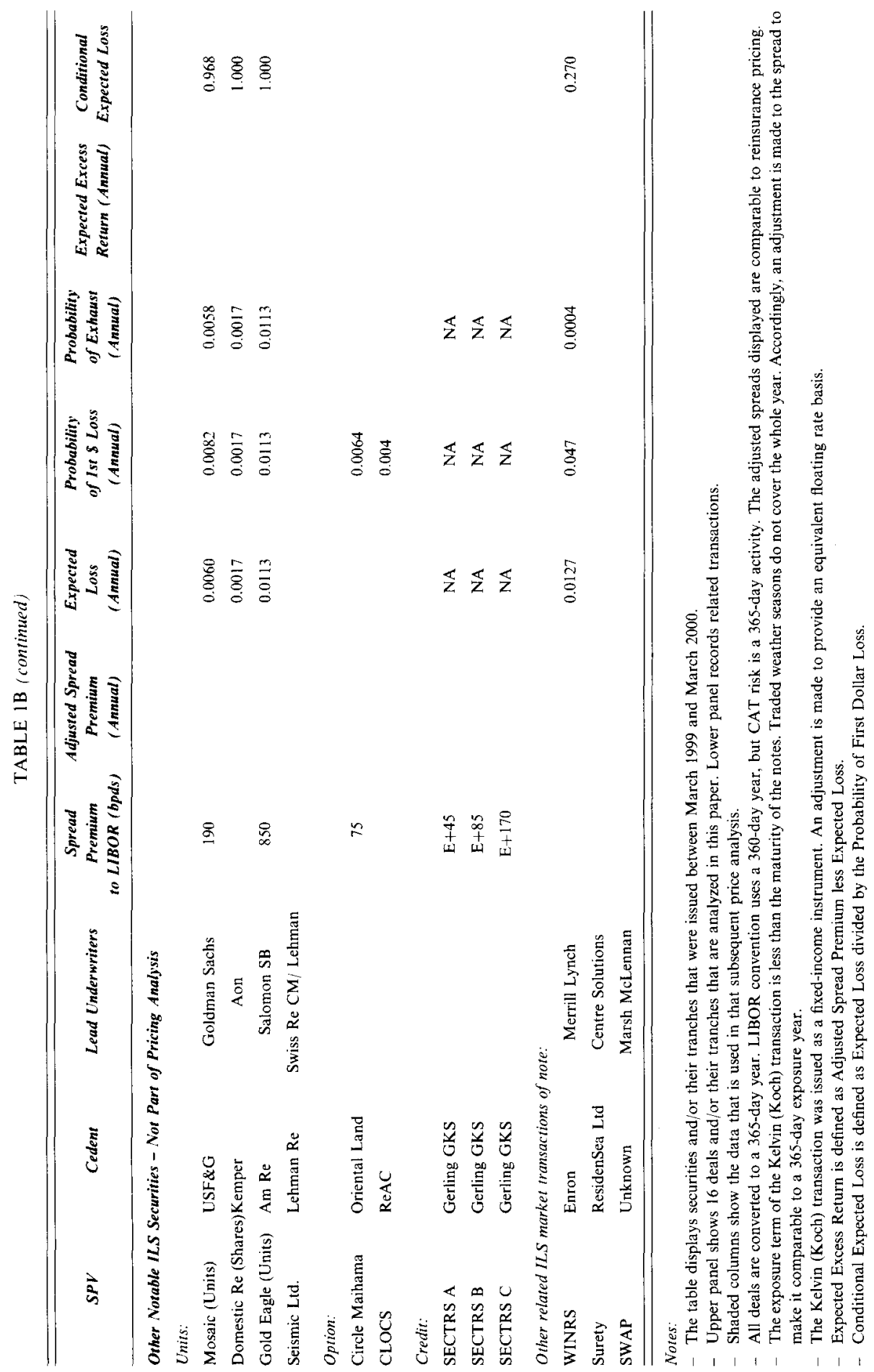


deals (i.e., Kelvin), to isolate the risk-price as opposed to the financing-price. (When deals are quoted on a floating rate basis (e.g., LIBOR plus a spread), that separation has already taken place.) The adjusted spread is now comparable to reinsurance quotations.

1999 was a decidedly active and experimental year. Particularly notable was the range and inventiveness of the deals brought to market. Deals covering earthquake and wind perils were repeated from the previous year (e.g., Mosaic, Residential $\mathrm{Re}$ ) and new deals were completed that combined or extended these risks (e.g., Halyard, Domestic, Concentric, Juno, Gold Eagle, Namazu, Atlas, Seismic). European wind and Midwest quake were added to the more familiar exposure regions. More importantly, two entirely new risk classes were securitized: weather (via Kelvin) and trade credit (via SECTRS). One company (Gerling) issued three securities - all different - making it second to USAA and Reliance who have both issued similar securities four times.

Several structural innovations stand out.

Domestic Re presented the market with the first use of a domestic SPV (via INEX). It is said that investor acceptance was thereby expanded. Certain classes of investor were not previously able to purchase ILS because of the offshore nature of the SPV.

Kelvin also stands out structurally. Not only did this security contain a new risk class (a portfolio of weather risks from U.S. cities) but the tranching was also unique. The so-called second event tranche was activated if and only if the first event had been previously attached - even if that first event tranche was not necessarily exhausted. Furthermore, the second event cover could only be brought on-risk at certain pre-specified dates. Once on risk, it would only attach after the first event exhausted. In the end, the nature of this tranching, combined with a new risk class, may have proved to be too complicated. Originally targeted as a $\$ 200$ million issue, the offering was closed after $\$ 54$ million.

Gold Eagle was based on a portfolio of equally sized "Industry Loss Warranty"-type covers. Each individual cover exhausted in full the moment it attached. Several such individual covers needed to attach to exhaust the junior tranche. The limit of the senior tranche was, however, set equal to the size of the individual covers. By design, it exhausted immediately when it was attached (i.e., $\mathrm{CEL}=100 \%$ ).

Seismic is also worthy of comment. Lehman Re bought index cover from Seismic Re using the PCS catastrophe index for California. Lehman Re was also known to have underwritten part of the California Earthquake Authority's traditional reinsurance placement. Lehman Re thereby created a basis risk for itself. This may be a harbinger of the way the ILS market will develop in the future.

Finally, by way of innovation, Concentric Re and Circle Maihama stand out. Concentric was not an issue from an insurer or reinsurer, but from the insured itself (Oriental Land). One potential consequence of insurance securitization is that the insured will bypass the insurance industry and go directly to the capital markets. This was the first concrete evidence of such disintermediation. The principle business of Oriental Land is Tokyo Disneyland. A sizeable earthquake 
anywhere in and around central Tokyo would affect Disneyland's business. Upon the occurrence of a specified earthquake, Concentric would immediately pay Oriental to compensate for business loss. The exact payment was based on a synthetically constructed scale (i.e., an index payment).

A sister part of Oriental Land's securitization was Circle Maihama. This was a standby facility. It allowed for Oriental Land debt issuance, and could be contingently activated if and only if Concentric was attached. The contingent debt provided Oriental Land with working capital.

The debt is to be issued on prearranged terms that will not change subsequent to an earthquake.

\section{PART II: COMPARING 1999 PRICES}

The gross price of a set of ILS securities issued at par may be expressed as the coupon accruing to the investor. As already observed, however, this is part financing-risk (LIBOR) and part insurance-risk (the spread over LIBOR). As the footnotes in Table 1 make clear, these spreads have to be adjusted to equivalent risk periods and day counts in order to make appropriate comparisons '. The true gross price of the insurance-risk is therefore, the "adjusted spread over LIBOR".

This adjusted spread can be broken down further into two parts. The first part compensates the investor for his expected losses (EL). The second part compensates the investor for assuming the risk of the investment. It is the amount the investor requires to commit his risk capital. Financial markets refer to this second spread as "expected excess return" (EER). This is what will be referred to as the price of a security - the net price, if you will.

In a riskless, perfect market, there would be no "expected excess return". However, these markets are not riskless and are demonstrably far from perfect. The risks taken are not obviously hedgeable and the investor needs a return to compensate for risks taken. The EER represents expected profit on the transaction over and above his financing return and expected losses. For the investor (the risk taker), the bigger the risk, the bigger the required expected profit. Even perfect-market financial theorists acknowledge that risk-adjusted returns will be higher for larger risks.

Reinsurance underwriters see the same thing but through a different lens. Underwriting premiums (pure prices - since there is no prefunding in traditional reinsurance) are viewed as consisting of expected losses plus a "load". Expected losses are defined as the same for both markets (presuming the same data and analyses). The "load" is therefore the insurance analogue of the "expected excess return". It is the price we seek to examine.

For the 1999 transactions, it varies considerably (See Table 2). The lowest "price" is in the $250+$ basis points range per annum (e.g., Concentric Re and the

${ }^{1}$ Credit quality is not an issue in these securities because they are fully funded. 
senior tranche of Atlas Re). The highest "price" is 1095 basis points (for the junior tranche of Atlas Re). Evidently, there is quite a range of riskiness.

TABLE 2

EXPECTED EXCESS REURNS (EER) VS FREQUENCY (PFL) AND SEVERITY (CEL) OF 1999 TRANSACTIONS

\begin{tabular}{lccc}
\hline \multicolumn{1}{c}{ Transaction } & EER & PFL & CEL \\
\hline Mosaic 2A & $0.0364^{*}$ & 0.0115 & 0.3652 \\
Mosaic 2B & 0.0552 & 0.0525 & 0.5410 \\
Halyard Re & 0.0393 & 0.0084 & 0.7500 \\
Domestic Re & 0.0324 & 0.0058 & 0.8621 \\
Concentric Re & 0.0272 & 0.0064 & 0.6563 \\
Juno Re & 0.0381 & 0.0060 & 0.7500 \\
Residential Re & 0.0327 & 0.0076 & 0.5789 \\
Kelvin 1st Event & 0.0652 & 0.1210 & 0.3678 \\
Kelvin 2nd Event & 0.0452 & 0.0156 & 0.1923 \\
Gold Eagle A & 0.0282 & 0.0017 & 1.0000 \\
Gold Eagle B & 0.0485 & 0.0078 & 0.8077 \\
Namazu Re & 0.0381 & 0.0100 & 0.7500 \\
Atlas Re A & 0.0263 & 0.0019 & 0.5789 \\
Atlas Re B & 0.0352 & 0.0029 & 0.7931 \\
Atlas Re C & 0.1095 & 0.0547 & 0.5923 \\
Seismic Ltd. & 0.0383 & 0.0113 & 0.6460 \\
\hline \hline
\end{tabular}

* The units are expressed here as decimal points of par. Thus, the Mosaic $2 \mathrm{~A}$ tranche investor expects to make a profit of $3.64 \%(0.0364)$ for taking a risk that has a $1.15 \%(0.0115)$ chance of happening. If a loss happens, it is expected that $36.52 \%(0.3652)$ of principal will be lost.

How are these relative prices determined? How does the market adjust for risk? In what follows, we are proposing fresh answers to these questions. Hopefully this will add new insight to an already rich debate on the subject of risk-pricing.

We also acknowledge entering this inquiry with certain prejudices (hopefully based on rational observation). First, we believe that one way to capture the asymmetric nature of loss distribution is to measure the "conditional expected loss" (CEL) from certain key threshold points (like the attachment point of the layer). Second, a most important risk measure is the probability that the cover will attach and that principal and interest will be impaired. Refer to this as the probability of first dollar loss (PFL).

The intuitive appeals of CEL and PFL are numerous. The chance of experiencing a loss is an obvious concern to any investor. It is also the stuff of rating agency evaluations. Although there is some debate between agencies about the exact interpretation of a rating in the context of insurance securities (Lane (12)), there is no debate about the interpretation for a simple corporate 
rating. It represents a ranking of the probability of default. Since that involves interest and/or principal, the rating is another name for a security's PFL.

Insurers refer to the PFL as frequency. If the annual probability of getting a loss is $1 \%$, then the interpretation is that the "frequency" is once every 100 years. In Table 2, PFLs range from $0.19 \%$ (Atlas senior tranche) to $12.1 \%$ (Kelvin junior tranche).

The CEL is the severity of a loss. If a loss happens (the conditional aspect), how big do you expect it to be? Obviously, the larger the potential hit, the higher (in some sense) is the riskiness of the security. More abstractly, the flatter the loss curve, the higher will be the CEL. In the extreme, if a loss is total, the CEL expressed as a percent - of exposure - will be $100 \%$. This is the case with the Gold Eagle senior tranche in the 1999 offerings. Contrast this with the Kelvin junior piece, where, if a hit happens, it is expected to result in only a $19 \%$ loss of principal. Given equal chances of being hit (i.e., the same PFLs), a rational investor would charge a much higher price for Gold Eagle than Kelvin.

Conversely, equivalent severity investments (i.e., equal CEL) would rank investment premiums by rating (i.e., PFL).

In short, there is a trade-off between the frequency and severity that must enter the risk-pricing framework. The precise empirical trade-off is presented in Table 2, which contains an extract of the essential financial statistics from Table 1B.

The hypothesis in examining 1999 prices is that the risk-price is a function of frequency and severity of loss.

$$
\mathrm{EER}=\text { Function }(\mathrm{PFL}, \mathrm{CEL})
$$

Further, we are emboldened by early analysis of the 1998 prices to suggest a functional form that is familiar to readers of old economic texts as a general form of the Cobb-Douglas Production Function vis-à-vis

$$
\mathrm{EER}=\gamma(\mathrm{PFL})^{\alpha} \times(\mathrm{CEL})^{\beta}
$$

Before proceeding to examine this and other possible relationships, we observe the special case where $\gamma=\alpha=\beta=1$. Then by definition

$$
\mathrm{EER}=\mathrm{PFL} \times \mathrm{CEL}=\text { Expected Loss. }
$$

In other words, if we found that $\gamma=\alpha=\beta=1$, that would validate the old fashioned "load" rule where the gross premium would be (in this case) twice the expected loss.

This observation also exposes the rule for determining the CEL of a security. All of the 1999 securities PPMs contain statistics on PFL and EL numbers. To extract the CEL, simply divide the EL by the PFL.

$$
\mathrm{CEL}=\mathrm{EL} \div \mathrm{PFL} \text {. }
$$

PFL is a number between 0 and 1 . The CEL will be a number between 0 and 1 , where 1 represents a $100 \%$ loss. Note also that we have chosen to express PFL and EL in terms of annual probabilities and annual expected loss. The 
probability of first dollar loss over the term to maturity of the investment could also be used, as long as it were consistently associated with total expected loss over the same term.

The intuitive appeal of the Cobb-Douglas form should not blind us to the possibility of other functional forms. The "Risk Cubes" paper provided extensive analysis of the linear form

$$
\mathrm{EER}=\gamma+\alpha \mathrm{PFL}+\beta \mathrm{CEL}
$$

with and without a specified intercept c. A respondent, Richard Phillips ${ }^{1}$ (Georgia State University), examined that data and suggested that our fit could be improved by a Taylor's expansion, at least to quadratic form vis-à-vis $\mathrm{EER}=\gamma 1+\alpha 1 \mathrm{PFL}+\beta 1 \mathrm{CEL}+\gamma 2+\alpha 2 \mathrm{PFL} 2+\beta 2 \mathrm{CEL} 2$. He further urged us to use the form where the intercept was included as part of the regression. As he observed, without the intercept, interpretations of R2 become problematic. For completeness, six regression fits of the data are conducted. The statistical results are displayed below in Table 3 .

1 Professor Phillip's assessment of the data is available on the web site, LaneFinancialLLC.com. 
TABLE 3

REGRESSION SUMMARY STATISTICS 1999 DATA SET

\begin{tabular}{|c|c|c|c|c|c|c|}
\hline \multirow{3}{*}{ Dependant } & Model 1 & Model 2 & Model 3 & Model 4 & Model 5 & Model 6 \\
\hline & \multicolumn{2}{|c|}{ Linear } & \multicolumn{2}{|c|}{ Quadratic } & \multicolumn{2}{|c|}{ Log Linear } \\
\hline & No Intercept & With Intercept & No Intercept & With Intercept & No Intercept & With Intercept \\
\hline Intercept & - & 0.0325 & - & 0.0161 & - & -0.5887 \\
\hline Std Err & & -0.02 & & 0.02 & & 0.28 \\
\hline (t-stat) & & 1.90 & & 0.74 & & -2.12 \\
\hline PFL & 0.6114 & 0.4404 & 1.7889 & 1.7557 & - & - \\
\hline Std Err & 0.14 & 0.15 & 0.38 & 0.39 & & \\
\hline (t-stat) & 4.52 & 2.87 & 4.69 & 4.48 & & \\
\hline CEL & 0.0456 & 0.0032 & 0.0519 & 0.0029 & -- & - \\
\hline Std Err & 0.01 & 0.02 & 3.14 & 0.07 & & \\
\hline (t-stat) & 6.19 & 0.14 & 1.60 & 0.04 & & \\
\hline $\mathrm{PFL}^{2}$ & - & - & -11.4199 & -11.3106 & - & - \\
\hline Std Err & & & 0.03 & 3.20 & & \\
\hline (t-stat) & & & -3.64 & -3.54 & & \\
\hline $\mathrm{CEL}^{2}$ & - & - & -0.0248 & 0.0110 & - & - \\
\hline Std Err & & & 0.04 & 0.06 & & \\
\hline (t-stat) & & & -0.65 & 0.18 & & \\
\hline LN(PFL) & - & - & - & - & 0.5955 & 0.4946 \\
\hline Std Err & & & & & 0.03 & 0.05 \\
\hline (t-stat) & & & & & 20.93 & 9.21 \\
\hline LN(CEL) & - & - & - & - & 0.7777 & 0.5741 \\
\hline Std Err & & & & & 0.21 & 0.21 \\
\hline (t-stat) & & & & & 3.72 & 2.79 \\
\hline $\mathbf{R}^{2}$ & 0.70 & 0.44 & 0.80 & 0.74 & 2.77 & 0.86 \\
\hline $\mathbf{R}^{2}$ Adjstd & 0.23 & 0.35 & 0.66 & 0.65 & -0.16 & 0.84 \\
\hline F Statistic & 13.60 & 5.03 & 11.80 & 7.91 & 35.93 & 43.64 \\
\hline$p$-value & 0.002437 & 0.024059 & 0.000684 & 0.002950 & 0.000033 & 0.000001 \\
\hline
\end{tabular}

The regressions show that the fit is improved by a complete form of the CobbDouglas equation vis-à-vis $\mathrm{ERR}=\gamma(\mathrm{PFL})^{\alpha} \times(\mathrm{CEL})^{\beta}$ and the best fit exists where $\gamma=55 \%, \alpha=49 \%$, and $\beta=57 \%$. (Note that $\gamma$ is the antilog of the estimate -0.5887 (i.e., $\ln (-0.5887)=0.55$.)

All parameters are statistically significant. Adjusted R2 is a healthy $84 \%$ and the $p$ value is extremely low - indicating an appropriateness of the fitted model.

The fitted equation

$$
\mathrm{EER}=0.55(\mathrm{PFL})^{0.495}(\mathrm{CEL})^{0.574}
$$


is different from the best fit of the 1998 ILS transaction. In that year, evidently a higher $\beta$ coefficient (around 2.2) indicated that greater pricing emphasis was being placed on severity of loss. However, the data set was smaller - a less good fit - and less well documented. We focus on the 1999 model.

One competitor to risk-pricing used extensively by investment bankers is the multiple of expected loss. In particular, it is used extensively to compare with bond pricing. The fitted form does not negate that approach. It simply refines it. In effect, the "multiple" is a function of both PFL and CEL".

\section{Visualization}

The fitted number can only tell part of the story. It is important to visualize exactly what is going on in this revealed preference function. Illustration is provided in two ways. First, imagine an underwriter pricing an excess-of-loss cover for four different underlying loss distributions - each cover incepting at the same cumulative probability of attachment - using the fitted model to calculate the "load". The picture is shown in Figure 2 and the numerical results are shown in Table 4. Clearly the effect of skewness of the various loss distributions is captured well in CEL numbers. More importantly, our fitted function provides load and total premiums that accord well with intuitive assumptions.

TABLE 4

RISK LOADS ON THE SAME COVER WHEN APPLIED TO DIFFERENT UNDERLYING DISTRIBUTIONS

\begin{tabular}{lccccc}
\hline & $\begin{array}{c}\text { Prob of } \mathbf{I}^{\text {st }} \\
\text { Loss }\end{array}$ & $\begin{array}{c}\text { Conditional } \\
\text { Expected Loss }\end{array}$ & $\begin{array}{c}\text { Expected } \\
\text { Loss }\end{array}$ & $\begin{array}{c}\text { Expected } \\
\text { Excess Return }\end{array}$ & $\begin{array}{c}\text { Spread over } \\
\text { LIBOR }\end{array}$ \\
\hline CovER: 5XS5 & PFL & CEL & EL & EER & SPREAD \\
DISTRIBUTIONS & Frequency & Severity & Burning Cost & Load & Premium \\
\hline Normal & 0.050 & $23.8 \%$ & $1.2 \%$ & $5.5 \%$ & 672 \\
Log Normal & 0.050 & $43.8 \%$ & $2.2 \%$ & $7.8 \%$ & 1004 \\
Gamma & 0.050 & $62.7 \%$ & $3.1 \%$ & $9.7 \%$ & 1281 \\
Discrete & 0.050 & $71.9 \%$ & $3.6 \%$ & $10.4 \%$ & 1403 \\
\hline \hline
\end{tabular}

1 Mathematical Equivalent of this statement:

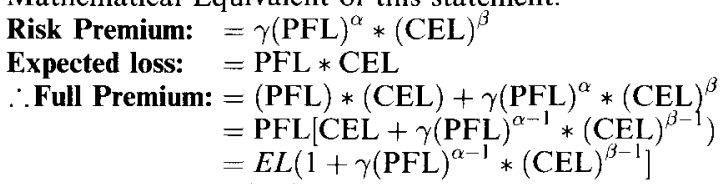

Full premium is indeed a multiple of Expected Loss. But the exact multiple will vary by CEL and PFL of the deal being considered. 


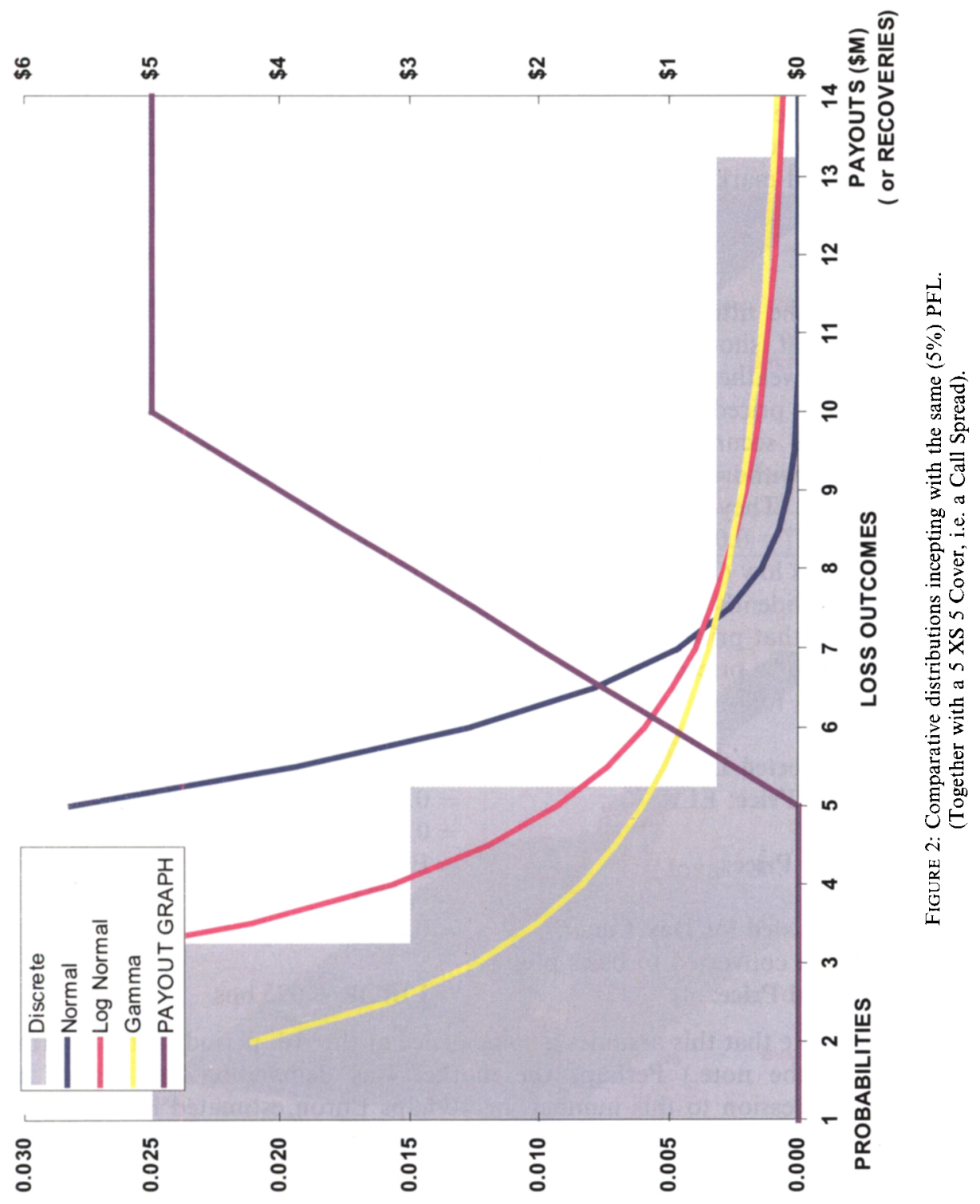


The second visualization is shown in panels A, B, C and D of Figure 3 - the process of fitting the cover - from coarse to smooth. Figure 3A shows the 1999 transacted prices as points of individual pyramids in three dimensional space (EER, PFL, CEL). Figure 3B shows the function

$$
\mathrm{EER}=0.55(\mathrm{PFL})^{0.495}(\mathrm{CEL})^{0.574}
$$

draped as it were over the price points. Certain securities stand out, as will be illustrated in the section on cheapness and dearness. Figure $3 \mathrm{C}$ shows the surface itself, and Figure 3D shows the trade-off between frequency and severity implicit in the modeled market.

\section{Extrapolation}

We can use the fitted parameters to suggest or predict the "load" or "risk premium" that should be attached to proposed securities. An interesting example is a weather bond proposed during 1999. What price should it have had if it was priced consistently with the other 1999 securities? "WINRS" was the 1999 security proposed by Merrill Lynch that was floated as a concept but withdrawn before issue. Its statistical specifications are listed in Table 1. They are $\mathrm{EL}=0.0127$ and $\mathrm{PFL}=0.047$. By deduction, $\mathrm{CEL}=(0.0127 \div 0.047)=0.2702$. WINRS was a weather bond like Kelvin, and its CEL is low (27\%) as was Kelvin's at $19 \%$. The cedent for WINRS was Enron who evidently did not like the market reaction and/or its market price. What should that price have been?

If it were to be priced consistent with the other 1999 securities, it would have been priced as follows:

Expected Loss:

Net Price: EER

Full Price:

Adjusted for Day Count:

And converted to basis points

Final Price:

$$
\begin{aligned}
& =0.0127 \\
& =0.55 \times(0.047)^{(0.4946)}(0.2702)^{(0.5741)} \\
& =0.0577 \\
& =\mathrm{EL}+\text { EER } \\
& =0.0704 \\
& =0.0695 \\
& =\mathrm{LIBOR}+695 \mathrm{bps}
\end{aligned}
$$

(Note that this assumes a coincidence of the risk period with the term of the note.) Perhaps the market was demanding too big of a concession to this number, or perhaps Enron estimated it was more expensive than other alternatives available to them and withdrew.

\section{Cheapness vs. Dearness}

One of the by-products of a model that coherently ties together all risk premiums of a set of securities is that their relative cheapness and dearness can be compared. That is illustrated for model 6 in Figure 4. The "when issued" 


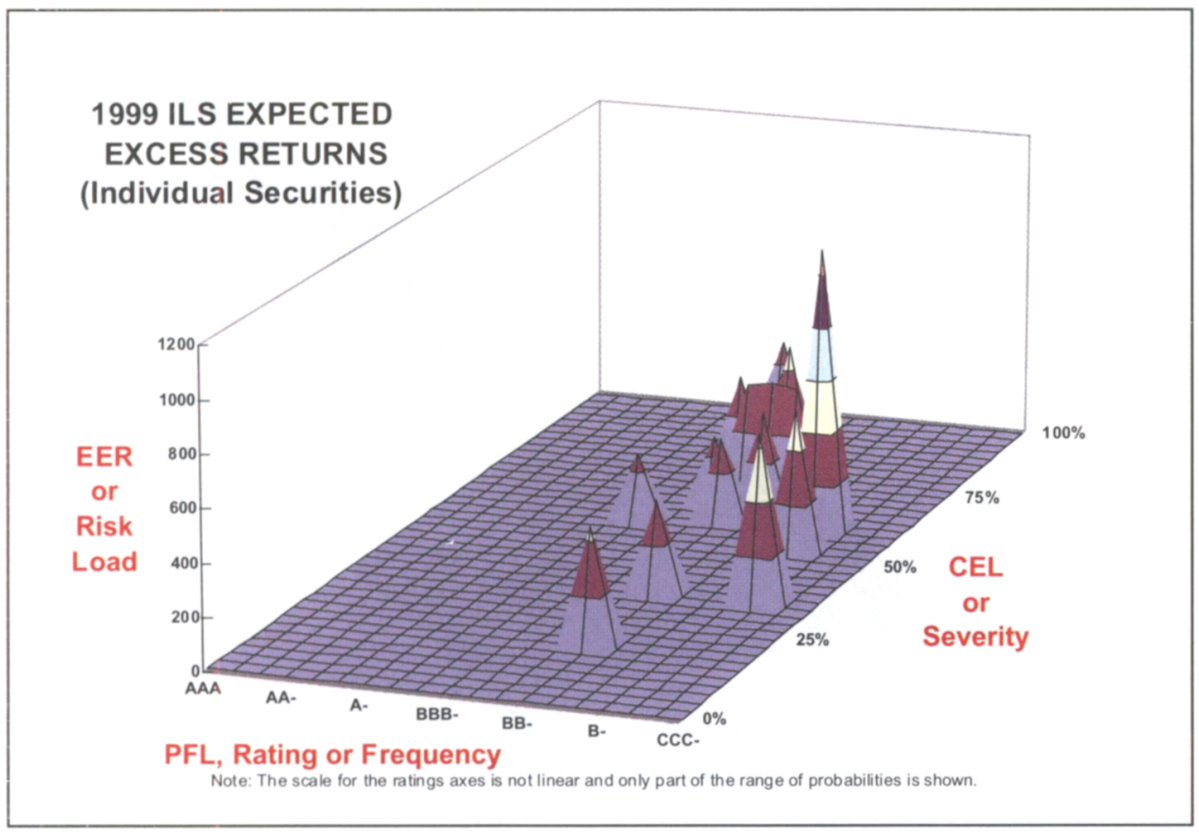

Figure 3B

1999 REVEALED RISKPREFERENCE SURFACE

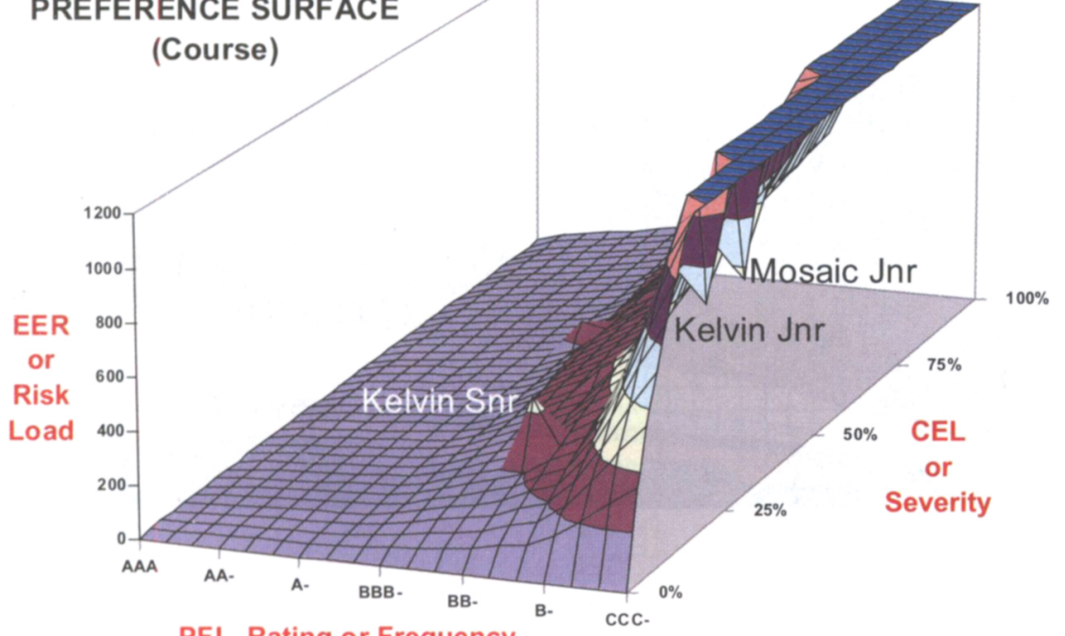

PFL, Rating or Frequency

Note: The scale for the ratings axes is not linear and only part of the range of probabilities is shown.

Figure 3: Transacted prices. 
Figure 3C

1999 REVEALED RISKPREFERENCE SURFACE (Smooth)

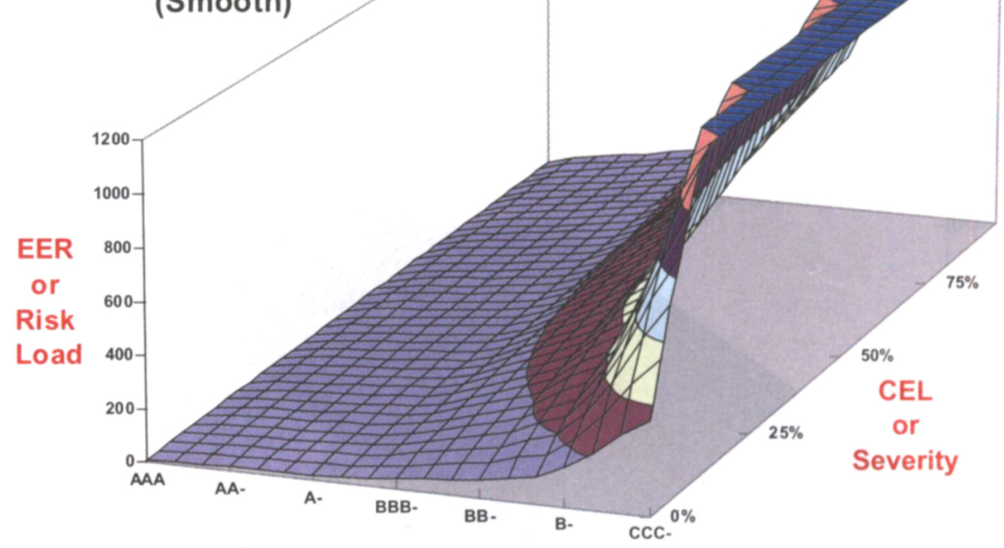

PFL, Rating or Frequency

Note: The scale for the ratings axes is not linear and only part of the range of probabilities is shown.

\section{Figure 3D}

1999 REVEALED RISK PREFERENCE INDIFFERENCE CURVES

(Vertical View)

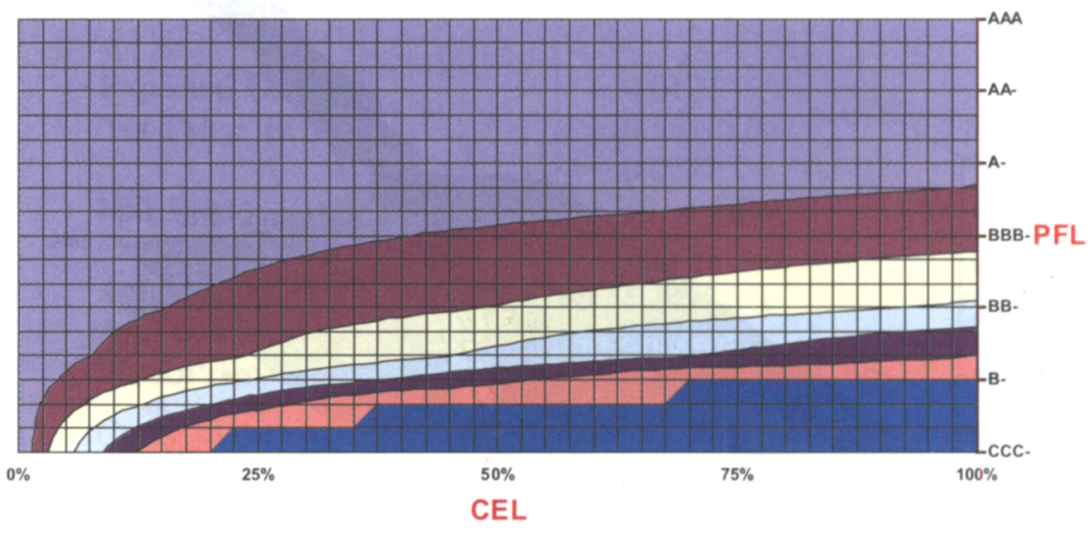

or

Severity

FIGURE 3 (continued): Transacted prices. 


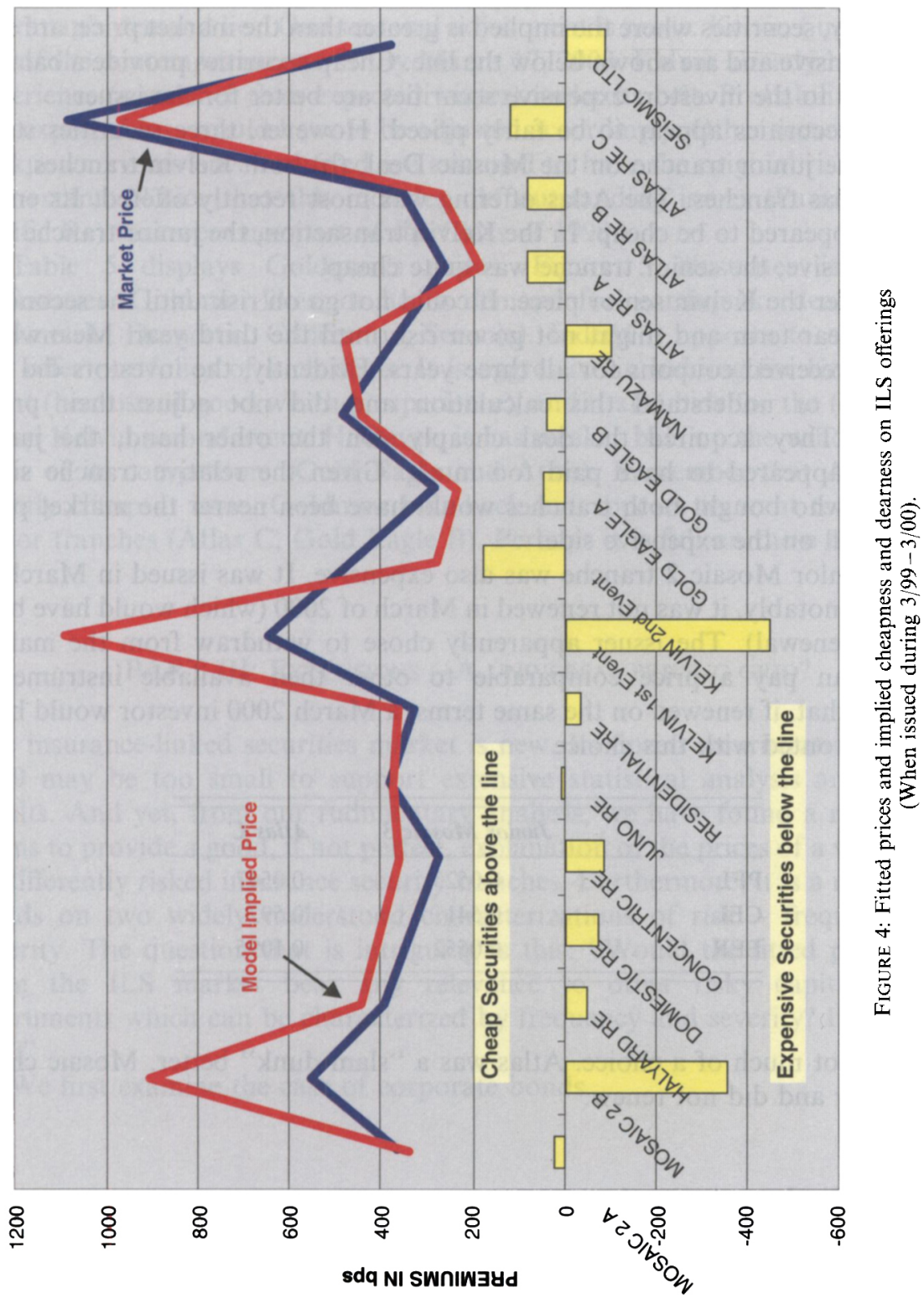


market price is plotted against the price as implied by the model. As one would expect from the R2, there is an appealing similarity in the curves. Also shown (in yellow bars) is the difference between the two lines. If the difference is positive (market price is greater than implied), the security is said to be "cheap". Conversely, securities where the implied is greater than the market price, are said to be expensive and are shown below the line. Cheap securities provide a balance of benefits to the investor; expensive securities are better for the issuer.

Most securities appear to be fairly priced. However, three securities stand out: (a) the junior tranche on the Mosaic Deal; (b) both Kelvin tranches, and (c) the Atlas tranches. The Atlas offering was most recently offered. Its entire offering appeared to be cheap. In the Kelvin transaction, the junior tranche was very expensive; the senior tranche was quite cheap.

Consider the Kelvin senior piece. It could not go on risk until the second of its three-year term and might not go on risk until the third year. Meanwhile, investors received coupons for all three years. Evidently, the investors did not appreciate or understand this calculation and did not adjust their prices upwards. They acquired the deal cheaply. On the other hand, the junior investors appeared to have paid too much. Given the relative tranche sizes, investors who bought both tranches would have been nearer the market price though still on the expensive side.

The junior Mosaic 2 tranche was also expensive. It was issued in March of 1999, and notably, it was not renewed in March of 2000 (which would have been its third renewal). The issuer apparently chose to withdraw from the market rather than pay a price comparable to other then available instruments. Consider that, if renewed on the same terms, a March 2000 investor would have been confronted with this choice

\begin{tabular}{lcl}
\hline & Junior Mosaic 3 & Atlas C \\
\hline PFL & 0.0525 & 0.0547 \\
CEL & 0.541 & 0.592 \\
EER & 0.0552 & 0.1095 \\
\hline \hline
\end{tabular}

There is not much of a choice. Atlas was a "slam-dunk" better. Mosaic chose not to pay and did not renew.

\section{Bidding: Weak vs. Aggressive}

The preceding analysis was on a "priced as when-issued" basis. It would be more intellectually appealing to have all the deals priced on the same day. This would avoid shifts in the market pricing that might have occurred between the issues becoming buried in the analysis. Fortunately, one market participant (Goldman Sachs) provides a consistent weekly bid and offer sheet allowing contemporaneous comparisons to be made. Unfortunately, such comparisons are not easy 
with insurance-linked notes. Exposure to insurance risk does not unfold at an even daily rate. Full comparison needs seasonal adjustment - something beyond the scope of this paper.

Nevertheless, an attempt has been made to compare the bids, to see where Goldman's demand lies. One seasonal adjustment is made: Kelvin (junior) is left out of the contemporaneous fit. By March 17, 2000, Kelvin already had a good experience (a warmer than expected winter) under its belt. Probabilities of loss and expected loss would have to be adjusted accordingly. Other securities where no known events have occurred are assumed to have the original risk statistics still extant. Notice that this includes old outstanding issues (Parametric Re, Pacific Re) that were not part of the Class of 1999.)

Table 5 displays Goldman's prices. Figure 5 illustrates its bidding preferences. Goldman likes, or has a demand for, earthquake deals (Pacific, Parametric, Domestic, Concentric, Seismic). Indeed it appears to accumulate and offer portfolios of such deals. It is aggressive in bidding for Kelvin's first event (because of good weather experience), and it also bids for the (originally) cheap Kelvin second event. However, it has weaker bids on the wind portfolio deals of its competitors (Gold Eagle and Atlas). Remember that Atlas came slightly cheap at issue. Goldman bids back but appears to want to avoid the junior tranches (Atlas C, Gold Eagle B). Perhaps it is full on these names.

\section{PART III: EXTENSIONS - A UNIVERSAL PRICING GRID?}

The insurance-linked securities market is new. Its dozen securitizations during 1999 may be too small to support extensive statistical analysis and reliable results. And yet, from our rudimentary analysis, we have found a model that seems to provide a good, if not perfect, explanation of the prices of a wide range of differently risked insurance security tranches. Furthermore, it is a model that builds on two widely understood characterizations of risk - frequency and severity. The question that is intriguing is this: "Would the fitted parameters from the ILS market bear any relevance to other risky capital market instruments which can be characterized by frequency and severity? If not, why not?"'

We first examine the case of corporate bonds.

\section{Corporate Bonds}

A senior, unsecured, AAA rated corporate credit is said by the rating agencies to have an annual probability of default of 1.5 basis points (i.e., probability of $0.00015)$. Triple-B securities are expected to default once every 588 years (i.e., probability of 0.0017 ). Their PFLs are respectively 0.00015 and 0.0017 and are shown with other bond ratings in Table 6 . 


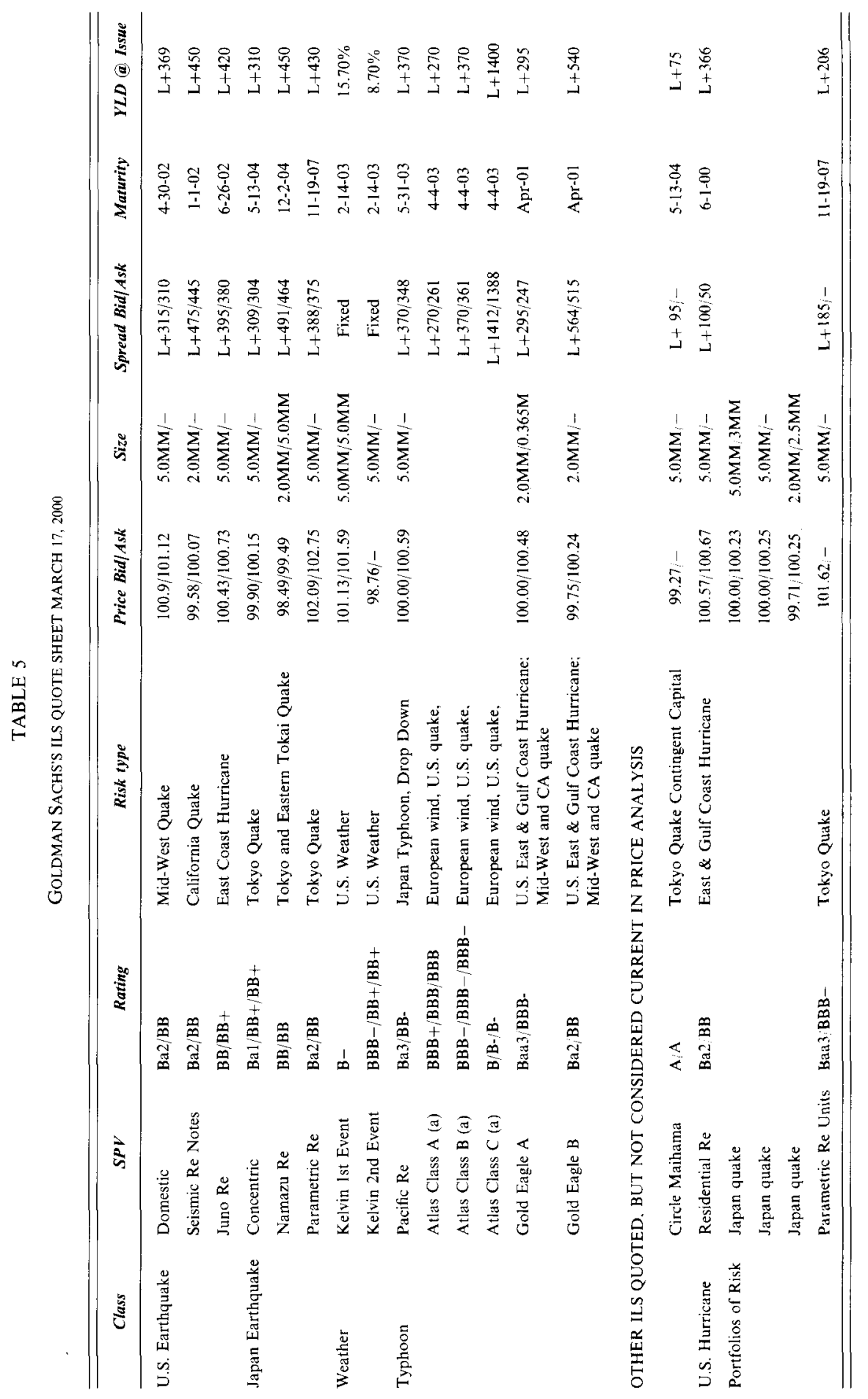




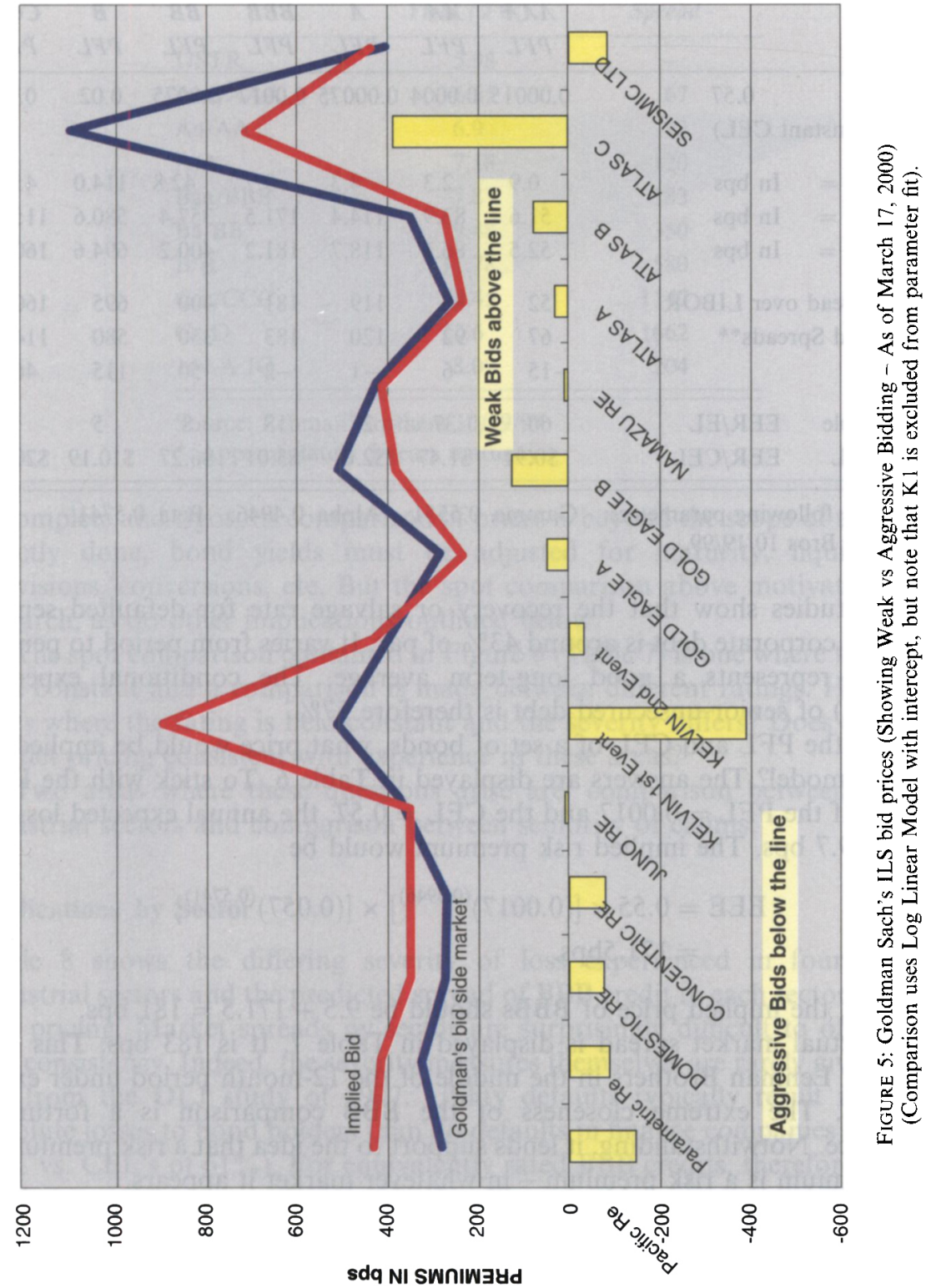


TABLE 6

PRICING CORPORATE BONDS FROM ILS'S REVEALED RISK PREFERENCE FUNCTION*

\begin{tabular}{|c|c|c|c|c|c|c|c|c|}
\hline & & $\begin{array}{c}\boldsymbol{A A A} \boldsymbol{A} \\
P F L\end{array}$ & $\begin{array}{c}\boldsymbol{A A} \\
P F L\end{array}$ & $\begin{array}{c}A \\
P F L\end{array}$ & $\begin{array}{c}\boldsymbol{B B B} \\
P F L\end{array}$ & $\begin{array}{c}\boldsymbol{B} \boldsymbol{B} \\
P F L\end{array}$ & $\begin{array}{c}\boldsymbol{B} \\
P F L\end{array}$ & $\begin{array}{l}C C C \\
P F L\end{array}$ \\
\hline \multicolumn{9}{|c|}{ (Assume constant CEL) } \\
\hline EL & In bps & 0.9 & 2.3 & 4.3 & 9.7 & 42.8 & 114.0 & 456.0 \\
\hline EER & In bps & 51.6 & 83.9 & 114.4 & 171.5 & 357.4 & 580.6 & 1152.6 \\
\hline $\mathrm{EL}+\mathrm{EER}=$ & In bps & 52.5 & 86.1 & 118.7 & 181.2 & 400.2 & 694.6 & 1608.6 \\
\hline Implied Spreac & over LIBOR & 52 & 86 & 119 & 181 & 400 & 695 & 1609 \\
\hline Actual Bond S & reads** & 67 & 92 & 120 & 183 & 350 & 580 & 1147 \\
\hline Difference & & -15 & -6 & -1 & -2 & 50 & 115 & 462 \\
\hline Risk Multiple & EER/EL & 60 & 37 & 27 & 18 & 8 & 5 & 3 \\
\hline$\$$ per $\$ 1 C E L$ & EER/CEL & $\$ 0.91$ & $\$ 1.47$ & $\$ 2.01$ & $\$ 3.01$ & $\$ 6.27$ & $\$ 10.19$ & $\$ 20.22$ \\
\hline
\end{tabular}

* Uses the following parameters: Gamma 0.5551; Alpha 0.4946; Beta 0.5741.

** Lehman Bros 10/19/99.

Various studies show that the recovery or salvage rate for defaulted senior, unsecured corporate debt is around $43 \%$ of par. It varies from period to period, but $43 \%$ represents a good long-term average. The conditional expected loss (CEL) of senior unsecured debt is therefore $57 \%$.

Given the PFL and CEL of a set of bonds, what price would be implied by the fitted model? The answers are displayed in Table 6. To stick with the BBB example, if the PFL $=0.0017$ and the $\mathrm{CEL}=0.57$, the annual expected loss on BBB's is 9.7 bps. The implied risk premium would be

$$
\begin{aligned}
\mathrm{EEE} & =0.55 \times\left[(0.0017)^{(0.4946)}\right] \times\left[(0.057)^{(0.5741)}\right] \\
& =171.5 \mathrm{bps} .
\end{aligned}
$$

Therefore, the implied price of BBBs should be $9.5+171.5=181 \mathrm{bps}$.

The actual market spread is displayed in Table 7. It is 183 bps. This was quoted by Lehman Brothers in the middle of the 12-month period under exam $(10 / 19 / 99)$. The extreme closeness of the BBB comparison is a fortunate coincidence. Notwithstanding, it lends support to the idea that a risk premium is a risk premium is a risk premium - in whatever market it appears.

Figure 6 shows the coincidence of pricing for all other corporates ratings. Diagrammatically, Figure 6 displays a tantalizing similarity between actual and ILS-implied bond prices. Closer examination of the Figure 6 (or Table 7) shows that the ILS market demands a higher premium than the bond market for the lower rated tranches. Last year it demanded a higher premium on senior tranches. Perhaps there is a novelty value to the new, more prolific, junior tranches in the ILS market. 
TABLE 7

CURRENT SPREADS FOR INTERMEDIATE* DEBT

\begin{tabular}{lcc}
\hline & Yield $($ TW $)$ & Spread \\
\hline USTR & 5.98 & - \\
Aaa/AAA & 6.65 & 67 \\
Aa/AA & 6.9 & 92 \\
$\mathrm{~A} / \mathrm{A}$ & 7.18 & 120 \\
$\mathrm{Baa} / \mathrm{BBB}$ & 7.81 & 183 \\
$\mathrm{Ba} / \mathrm{BB}$ & 9.48 & 350 \\
$\mathrm{~B} / \mathrm{B}$ & 11.78 & 580 \\
$\mathrm{Ccc} / \mathrm{CCC}$ & 17.45 & 1147 \\
$\mathrm{Cc} / \mathrm{D}$ & 22.6 & 1662 \\
144-A IG & 8.02 & 204 \\
\hline \hline
\end{tabular}

Source: Lehman Brothers 10/19/99.

* Approximately 5 years maturity.

A complete and rigorous comparison of prices is beyond the scope of this paper. Strictly done, bond yields must be adjusted for maturity, liquidity, call provisions, conversions, etc. But the spot comparison above motivates further research, as do other implications outlined below.

The spot comparison contained in Figure 6 (Table 7) is one where the CEL is held constant and a comparison is made between different ratings. How about deals where the rating is held constant and the severity differs? Does the model predict pricing consistent with experience in these areas?

Two areas where these questions arise are: comparison between different industrial sectors and comparison between seniority of claims.

\section{Implications by Sector}

Table 8 shows the differing severity of loss experienced in four different industrial sectors and the predicted spread of BBB credit in each sector based on ILS pricing. Market spreads by sector are surprisingly difficult to obtain with any consistency. Indeed, the severity measures themselves are rarely given. These are from the DLJ study of 1997. Utility defaults typically result in smaller absolute losses to bond holders than do defaults in finance companies (CEL's of $39 \%$ vs. CEL's of $61 \%$ ). For equivalently rated BBB credits, therefore, the ILS market suggests that utility bonds should trade 44 bps more expensive than bonds from the finance sector (145 bps vs. 189). Other industrial sectors should display similar discounts to utilities (manufacturing $19 \mathrm{bps}$ for example). While exact market comparisons are difficult, a recent spot check of BBB securities by sector showed Finance-Utility spreads of 48 bps and Manufacturing-Utility spreads of $28 \mathrm{bps}$. 


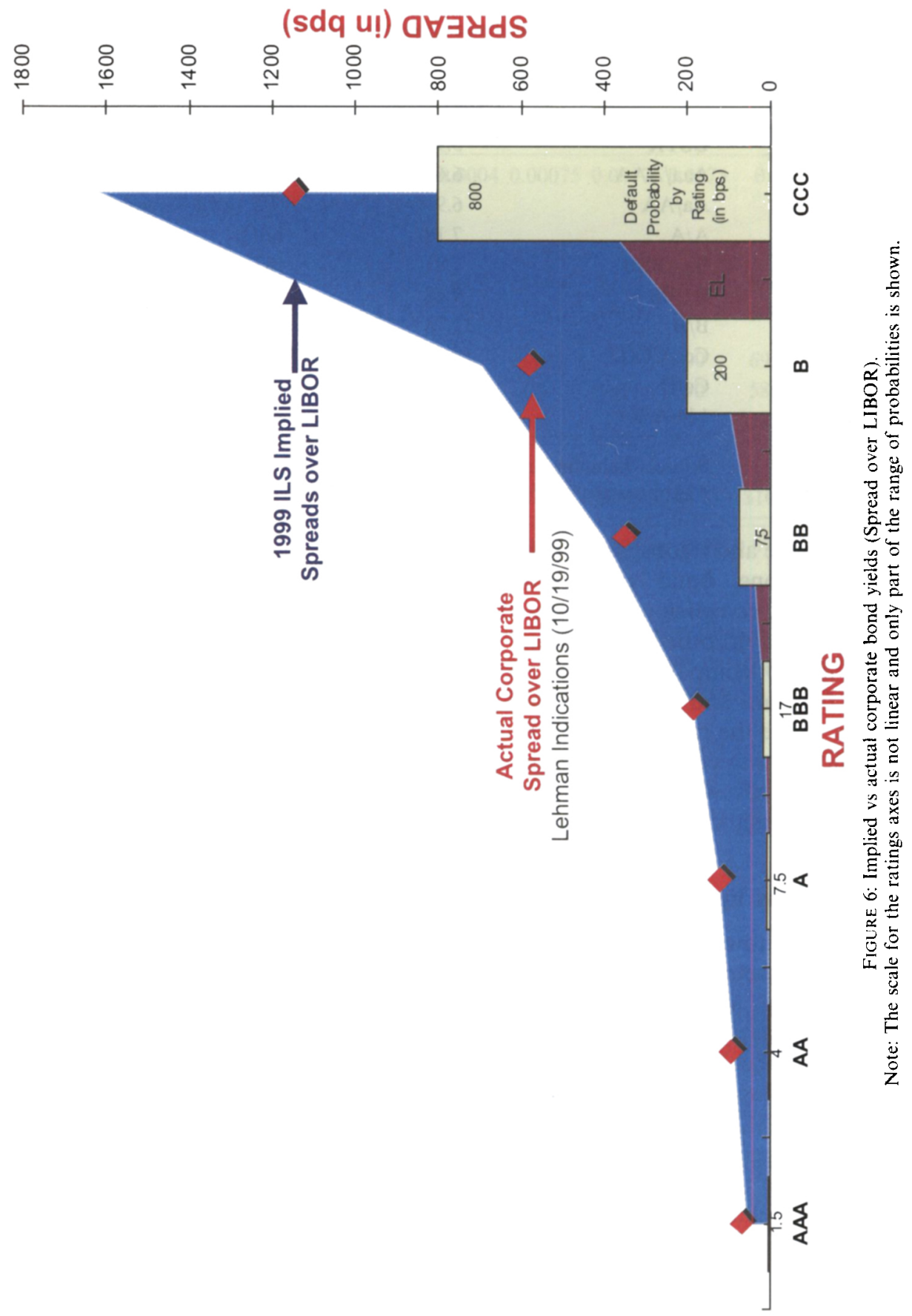


TABLE 8

SEVERITY OF LOSS BY INDUSTRY

\begin{tabular}{lcc}
\hline $\begin{array}{c}\text { Industry } \\
\text { (BBB rated) }\end{array}$ & $\begin{array}{c}\text { CEL } \\
\text { (Approx) }\end{array}$ & $\begin{array}{c}\text { Implied } \\
\text { Spread }\end{array}$ \\
\hline Utilities & $39 \%$ & 145 \\
Energy & $41 \%$ & 149 \\
Manufacturing & $48 \%$ & 164 \\
Consumer Durables & $63 \%$ & 192 \\
Finance & $61 \%$ & 189 \\
\hline
\end{tabular}

* Source: DLJ Default Study.

\section{Implications by Seniority}

Similar comparisons can be made between the seniority of claim of bondholders. In distress situations, different claimants for the remaining assets rank ahead of others. Senior secured debt is first, junior debt is last. The amount of loss each class experiences is therefore the average severity of loss or CEL (see Table 9). Given a set of equivalently rated BB tranches, the ILS pricing model would predict a spread of 138 bps between senior secured debt and junior subordinated debt ( 351 bps vs. 479 bps).

TABLE 9

SEVERITY OF LOSS BY SENIORITY

\begin{tabular}{lcc}
\hline $\begin{array}{c}\text { Seniority } \\
\text { (BB rated) }\end{array}$ & $\begin{array}{c}\text { CEL* } \\
\text { (Approx) }\end{array}$ & $\begin{array}{c}\text { Implied } \\
\text { Spread }\end{array}$ \\
\hline Senior Secured & $46 \%$ & 351 \\
Senior Unsecured & $57 \%$ & 400 \\
Senior Subordinated & $64 \%$ & 430 \\
Junior Subordinated & $76 \%$ & 479 \\
\hline
\end{tabular}

* Source: DLJ Default Study.

In practice, such comparisons are difficult to make because not all debt of different seniority is rated the same. And, not all industrial sectors issue in the same rating classes. Market spreads therefore might be wider or narrower than predicted here. Our objective, however, is not to predict spread. Rather, it is to illustrate the virtues of a revealed preference function that utilizes both frequency and severity as components of risk pricing. It appears to be consistent with the way the bond market discriminates between credits. One other example may drive the point home: leveraged loans and general corporates. 


\section{Implications for Leveraged Loans}

The "leveraged loan" market is increasingly a traded market where market prices are obtainable. Leveraged loans are loans to sub-investment grade borrowers that nevertheless have senior secured claims in default. Their severity of loss is reckoned to be very low (CEL $\leq 20 \%$ ). Compared to an equivalently risked corporate, the ILS revealed risk preference function would predict an 83 bps differential between leveraged loans and corporates vis-à-vis:

\begin{tabular}{lcc}
\hline & $\begin{array}{c}\text { Leveraged Loans } \\
(\boldsymbol{B B B} \text { rated })\end{array}$ & $\begin{array}{c}\text { Corporate } \\
(\boldsymbol{B B B} \text { rated })\end{array}$ \\
\hline PFL & 0.0017 & 0.0017 \\
CEL & 0.20 & 0.57 \\
Risk Premium & 0.94 & 171.5 \\
Adjusted Spread & $96 \mathrm{bps}$ & $179 \mathrm{bps}$ \\
\hline
\end{tabular}

This is somewhat consistent with market observation.

Another discrepancy that exists in credit markets is the price differential between equivalently rated corporates and CBO or CLO tranches. The explanation to this spread we believe also emanates from CEL differentials, though detailed examination is beyond us here.

In this section we have demonstrated that the fitted revealed risk preference from the ILS market has plausible implications for other fixed income markets. However, in no way do we assert the superiority of the ILS market. To the contrary, the bond market is bigger, deeper, more liquid, and longer lived as a traded market. It should dictate risk preferences to the ILS market not the other way around. But as far as we know, no one has tried to explain prices in either market in quite the way done here. To our mind, it calls for an empirical study of corporate bonds to gauge the risk-return trade-offs implicit in the credit markets.

\section{Two Way Rating System - A Suggestion}

We could not leave this discussion of risk-pricing without a call to rating agencies to enhance their categorizations. They do a magnificent job of grading all sorts of credits by the likelihood that the credit will fail to honor its obligations - to default. However, this "frequency estimate" is only one dimension of risk assessment and therefore of risk pricing. Severity is as important as frequency. Why not rate credits on both dimensions - a two-way system? 
TABLE 10

RISK PRICING BY TWO-WAY RATING (USING FITTED* ILS PRICES)

\begin{tabular}{|c|c|c|c|c|c|c|c|c|c|}
\hline & & & $\begin{array}{c}\boldsymbol{P F L} \\
0.00015\end{array}$ & $\begin{array}{c}P F L \\
0.0004\end{array}$ & $\begin{array}{c}P F L \\
0.00075\end{array}$ & $\begin{array}{c}P F L \\
0.0017\end{array}$ & $\begin{array}{c}\boldsymbol{P F L} \\
0.0075\end{array}$ & $\begin{array}{c}P F L \\
0.02\end{array}$ & $\begin{array}{l}P F L \\
0.08\end{array}$ \\
\hline \multicolumn{10}{|c|}{ EXPECTED LOSS (EL) } \\
\hline & & & $A A A$ & $A A$ & $A$ & $B B B$ & $B B$ & $B$ & $C C C$ \\
\hline CEL & $20 \%$ & I & 0.3 & 0.8 & 1.5 & 3.4 & 15.0 & 40.0 & 160.0 \\
\hline OR & $40 \%$ & II & 0.6 & 1.6 & 3.0 & 6.8 & 30.0 & 80.0 & 320.0 \\
\hline SEVERITY & $60 \%$ & III & 0.9 & 2.4 & 4.5 & 10.2 & 45.0 & 120.0 & 480.0 \\
\hline $\mathrm{OF}$ & $80 \%$ & IV & 1.2 & 3.2 & 6.0 & 13.6 & 60.0 & 160.0 & 640.0 \\
\hline LOSS & $100 \%$ & $\mathrm{~V}$ & 1.5 & 4.0 & 7.5 & 17.0 & 75.0 & 200.0 & 800.0 \\
\hline \multicolumn{10}{|c|}{ EXPECTED EXCESS RETURN (EER)* or "LOAD" } \\
\hline & & & $\boldsymbol{A} \boldsymbol{A A}$ & $A A$ & $A$ & $B B B$ & $B B$ & $\boldsymbol{B}$ & $C C C$ \\
\hline CEL & $20 \%$ & $\mathrm{I}$ & 28.3 & 46.0 & 62.7 & 94.0 & 195.9 & 318.3 & 631.8 \\
\hline OR & $40 \%$ & II & 42.1 & 68.4 & 93.4 & 140.0 & 291.7 & 473.8 & 940.5 \\
\hline SEVERITY & $60 \%$ & III & 53.2 & 86.4 & 117.9 & 176.7 & 368.1 & 598.0 & 1187.0 \\
\hline $\mathrm{OF}$ & $80 \%$ & IV & 62.7 & 101.9 & 139.0 & 208.4 & 434.2 & 705.3 & 1400.2 \\
\hline LOSS & $100 \%$ & $\mathrm{~V}$ & 71.3 & 115.8 & 158.0 & 236.9 & 493.6 & 801.7 & 1591.5 \\
\hline \multicolumn{10}{|c|}{ SPREAD OVER LIBOR (EL + EER) } \\
\hline & & & $A A A$ & $A A$ & $A$ & $B B B$ & $B B$ & $\boldsymbol{B}$ & $C C C$ \\
\hline CEL & $20 \%$ & $\mathrm{I}$ & 28.6 & 46.8 & 64.2 & 97.4 & 210.9 & 358.3 & 791.8 \\
\hline OR & $40 \%$ & II & 42.7 & 70.0 & 96.4 & 146.8 & 321.7 & 553.8 & 1260.5 \\
\hline SEVERITY & $60 \%$ & III & 54.1 & 88.8 & 122.4 & 186.9 & 413.1 & 718.0 & 1667.0 \\
\hline $\mathrm{OF}$ & $80 \%$ & IV & 63.9 & 105.1 & 145.0 & 222.0 & 494.2 & 865.3 & 2040.2 \\
\hline LOSS & $100 \%$ & $\mathrm{~V}$ & 72.8 & 119.8 & 165.5 & 253.9 & 568.6 & 1001.7 & 2391.5 \\
\hline
\end{tabular}

Data presented in annual basis points.

* Uses the following parameters: Gamma 0.5551; Alpha 0.4946; Beta 0.5741.

To illustrate how this might work, consider Table 10. It shows a matrix classification of risks and a current estimate of pricing in each class. The vertical classification is the conventional rating analysis using, in this case, S\&P classifications. The horizontal strata is simply a division of risks in to different CEL classes, labeled I to $V$ for each $20 \%$ interval.

Thus, a II/AA risk would have a loss severity of between $20 \%$ to $40 \%$ and a likelihood of default of 0.0004 per annum. A deep out-of-the-money weather call comes to mind. It would be priced at approximately LIBOR +70 bps. A IV/ B security would imply loses around $60 \%$ to $80 \%$ and a likelihood of occurrence of $2 \%$. Priced consistent with the ILS market, it should command LIBOR +865 . Interestingly, equity which could be viewed as having a CCC chance of almost total loss should carry a spread of close to $25 \%$ - very similar to what is anticipated for equity over and above the risk-free rate. 


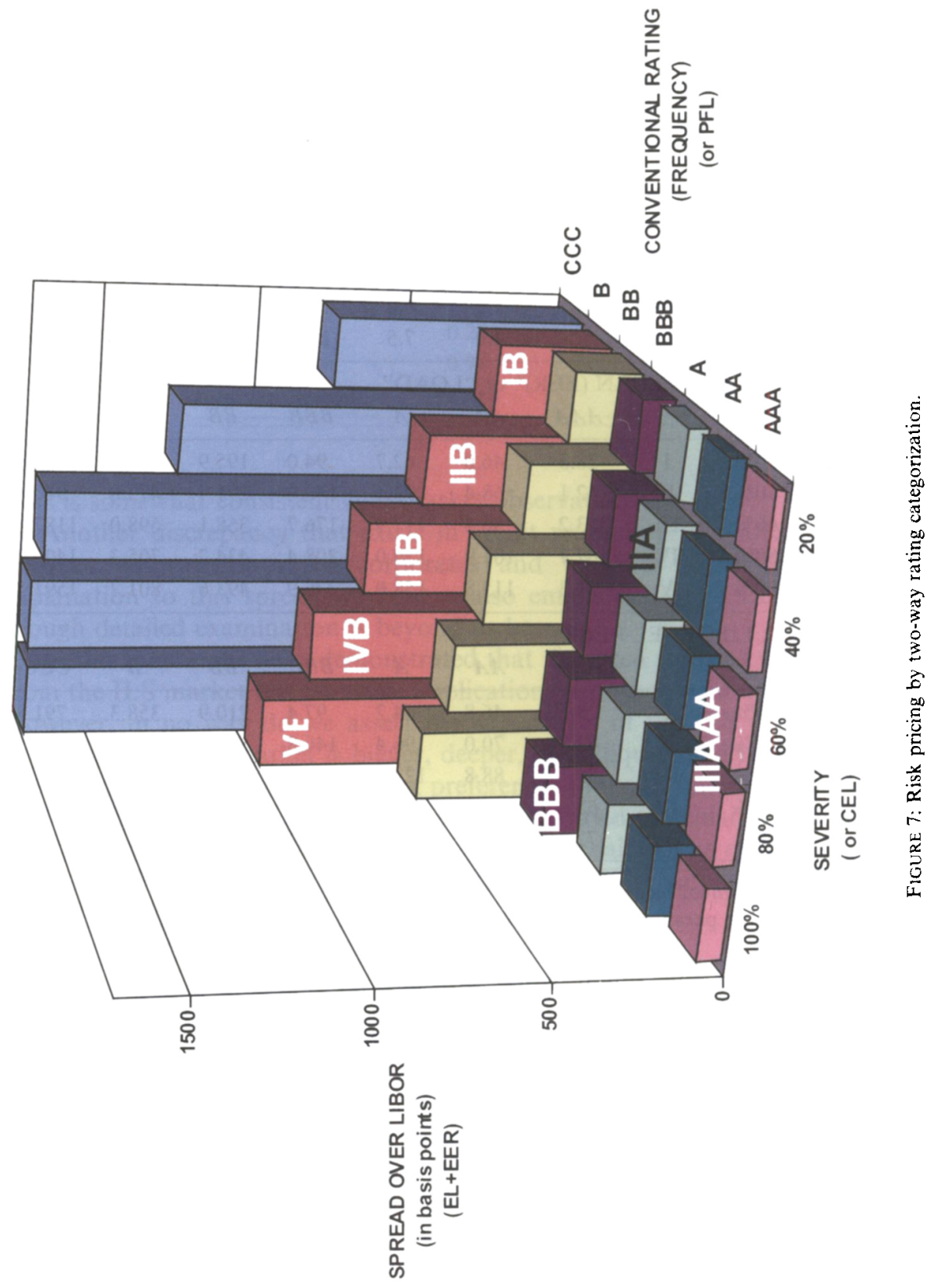


More exploration of two-way rating is not appropriate here. Suffice it to say that we believe such a system would be a boon to investors and a welcome new product for the agencies themselves.

\section{Concluding Remarks}

This paper has done three things. First, it has presented a record of insurance securitizations that occurred between March 1999 and March 2000.

Second, it has fitted a function to transacted prices that goes a long way to explaining those 1999 prices in terms of the frequency and severity of loss. The fitted function is a "utility function" or a "revealed risk preference" function that is well ordered, and satisfies the basic requirements of such functions. We have illustrated the usefulness for comparing relative cheapness and dearness of ILS prices and for discriminating between weak versus aggressive bidding patterns.

Thirdly and finally, the paper has sought to explore the implications of this risk-pricing in the context of corporate bonds. Both corporate credit risk and insurance risk is locally non-hedgeable and might be expected to carry similar risk premiums. The exploration is persuasive enough to motivate a large empirical study of risk premium in the bond market. Joint estimation of risk preferences should then lead to superior insights for insurance risk managers and portfolio investment managers alike.

Beyond the base line observations, we think that the admission of the existence of a universal pricing grid or utility function can lead to some important insights in other contexts. Consider VAR (Value-at-Risk) as a risk management tool. Always controversial, VAR sets a (PFL) level as a mechanism to control risk taking. However, the 1998 credit crunch accompanied by the collapse of Long Term Capital Management have caused some to want to also control the conditional loss beyond the VAR attachment point. It is referred to in the literature as controlling "conditional tail loss", but essentially it is about controlling severity once an acceptable frequency of loss has been agreed upon. Anyone doubting that equal VAR points can have differing "conditional tail loss" might flip back to Figure 2, Table 4 to refresh their ideas on how underwriters view such risks.

Another context where frequency and severity questions are increasingly being asked is in the performance of hedge funds. One analyst, Leah Modigliani (16) at Morgan Stanley insists that performance returns should be adjusted for (among other things) frequency of draw downs (losses) and the severity of such losses. It seems that she is asking whether the ex-post performance of funds is consistent with market trade-offs between these two risk measures. Our ex-ante trade-offs estimate might well contribute to that analysis.

Whatever the financial context, the use of revealed frequency and severity trade-offs exposes some fascinating new vistas and some intriguing questions. For example, can the individual frequency/severity trade-off parameters be used for the whole investment portfolio? Can they be used by the reinsurer to gauge 
where to take leverage in his book - in reinsurance or investments? Can the shifting spreads in the bond market be ascribed to revised probability estimates or to changing risk preferences? How can the two be distinguished?

In summation, thinking about ILS securities has led to thinking about credit risks. This cross fertilization exercise has, we believe, many important implications for further future examination.

\section{REFERENCES}

1. Bantwal, V.J. and Kunreuther, H. C. (2000) A Cat Bond Premium Puzzle? In The Journal of Psychology and Financial Markets, Vol. 1, No.1, 76-91.

2. Blume, M.E., DonAld, B.K. and SA A.P. (1991) Returns and the Volatility of Low Grade Bonds. Journal of Finance 44: 909-922.

3. Canabarro, E., Finkemeier, M., Anderson, R.R. and Bendimerad, F. Analyzing Insurance-Linked Securities," The Journal of Risk Finance, Volume 1, No. 2, 49-75.

4. DeRosa-Farag, S., Blau, J., Matousek, P, Chandra, I., Jaggi, H. and ReifF, A. (1998) Default Rates in the High Yield Market: An Examination Within the Context of Overall Market Risk. Donaldson, Lufkin 7 Jenrette Securities Corporation.

5. Elton, E., and MARTin J.G. (2000) Explaining the Rate Spread on Corporate Bonds forthcoming. Journal of Finance.

6. Froot, K.A. and Posner, S. (2000) Issues in the Pricing of Catastrophe Risk. Guy Carpenter Marsh \& McLennan Securities White Papers. May 2000. < http://www.guycarp. com/publications/white/whitep.html >

7. Kealhofer, S., KwoK, S. and Weng, W. (1998) Uses and Abuses of Bond Default Rates. KMV, LLC: Industry Insider: Technical Papers. 3 March 1998. < http://www.kmv.com/ docs/documents.html >

8. KREPS, R.E. (1990) Reinsurer Risk Loads from Marginal Surplus Requirements. PCAS LXXVII, 1990.

9. KREPS, R.E. (1998) Investment-Equivalent Reinsurance Pricing. 1998 PCAS Proceedings. Also available from Guy Carpenter Instrat Publications, 14 February 2000. < http: //www.guycarp.com/products/dorweil/kreps.html >

10. Lane, M.N. and Beckwith, R.G. (2000) Trends in the Insurance-Linked Securities Market. Lane Financial L.L.C. Trade Notes, May 31, 2000. < http://www.lanefinancialllc. com>

11. Lane, M.N. and Movchan, O.Y. (1999) Risk Cubes or Price, Risk and Ratings (Part II). Sedgwick Lane Financial LLC Trade Notes, March 15, 1999. < http://www.lanefinanciallic. com >

12. LANE, M.N. (1998) Price, Risk and Ratings for Insurance-Linked Notes: Evaluating Their Position in Your Portfolio. Derivatives Quarterly, Spring 1998. Based on a presentation made before the conference, "Rethinking Insurance Regulation 1998" sponsored by the Competitive Enterprise Institute in Washington, DC on April 13, 1998. <http://www. lanefinancialllc.com $>$

13. LANe, M.N. (1997) A Year of Structuring Furiously: Promises, Promises... Sedgwick Lane Financial LLC Trade Notes, January 31, 1997. Also published in Energy Insurance Review, Spring 1997. <http://www.lanefinancialllc.com>

14. Litzenberger, R.H., Beaglehole, D.R. and Reynolds, C.E. (1996) Assessing Catastrophe Reinsurance-linked Securities as a New Asset Class. Journal of Portfolio Management (December): 76-86.

15. Mango, D. (1999) Risk Load and the Default Rate of Surplus. In Casualty Actuarial Society 1999 Discussion Papers on Securitization Risk. <http://www.casact.org/pubs/dpp/ dpp99/index.htm > 
16. Modigliani, L. (1997) Investment Strategy: Are Hedge Funds Worth the Risk? In Morgan Stanley U.S. Investment Research (December 12, 1997).

17. Van de Castle, K. and Keisman, D. (1999) Recovering Your Money: Insights Into Losses From Defaults. In Standard \& Poor's Credit Week, June 16, 1999, 29-34.

\section{MORTON LANE}

Lane Financial LLC

321 Melrose Avenue

Kenilworth

IL 60043-1136

$U S A$ 